\title{
FLOWERING DATE OF TAXONOMIC FAMILIES PREDICTS PHENOLOGICAL SENSITIVITY TO TEMPERATURE: IMPLICATIONS FOR FORECASTING THE EFFECTS OF CLIMATE CHANGE ON UNSTUDIED TAXA ${ }^{1}$
}

\author{
Susan J. Mazer ${ }^{2,3,13}$, Steven E. Travers ${ }^{4}$, Benjamin I. Cook ${ }^{5,6}$, T. Jonathan Davies ${ }^{7}$, \\ Kuell Bolmgren $^{8,9}$, Nathan J. B. Kraft ${ }^{10}$, Nicolas Salamin ${ }^{11}$, and David W. Inouye ${ }^{10,12}$ \\ ${ }^{2}$ Department of Ecology, Evolution and Marine Biology, University of California-Santa Barbara, Santa Barbara, California \\ 93106 USA; ${ }^{3}$ Stellenbosch Institute for Advanced Study (STIAS), ZA-7600, Mostertsdrift, Private Bag X1, Matieland 7602, \\ South Africa; ${ }^{4}$ Department of Biological Sciences, North Dakota State University, Fargo, North Dakota, 58102, USA; ${ }^{5}$ NASA \\ Goddard Institute for Space Studies, New York, New York, 10025, USA: ${ }^{6}$ Ocean and Climate Physics, Lamont-Doherty Earth \\ Observatory, Palisades, New York, 10964, USA: ${ }^{7}$ Department of Biology, McGill University, Montreal, QC H3A 0G4, Canada; \\ ${ }^{8}$ Theoretical Population Ecology and Evolution Group, Lund University, 221 00, Lund, Sweden; ${ }^{9}$ Swedish National Phenology \\ Network, Swedish University of Agricultural Sciences, SE-360 30 Lammhult, Sweden; ${ }^{10}$ Department of Biology, University of \\ Maryland, College Park, Maryland 20742 USA: ${ }^{11}$ Swiss Institute of Bioinformatics, Quartier Sorge, 1015 Lausanne, \\ Switzerland; and ${ }^{12}$ Rocky Mountain Biological Laboratory, Crested Butte, Colorado 81224 USA
}

- Premise of the study: Numerous long-term studies in seasonal habitats have tracked interannual variation in first flowering date (FFD) in relation to climate, documenting the effect of warming on the FFD of many species. Despite these efforts, long-term phenological observations are still lacking for many species. If we could forecast responses based on taxonomic affinity, however, then we could leverage existing data to predict the climate-related phenological shifts of many taxa not yet studied.

- Methods: We examined phenological time series of 1226 species occurrences (1031 unique species in 119 families) across seven sites in North America and England to determine whether family membership (or family mean FFD) predicts the sensitivity of FFD to standardized interannual changes in temperature and precipitation during seasonal periods before flowering and whether families differ significantly in the direction of their phenological shifts.

- Key results: Patterns observed among species within and across sites are mirrored among family means across sites; earlyflowering families advance their FFD in response to warming more than late-flowering families. By contrast, we found no consistent relationships among taxa between mean FFD and sensitivity to precipitation as measured here.

- Conclusions: Family membership can be used to identify taxa of high and low sensitivity to temperature within the seasonal, temperate zone plant communities analyzed here. The high sensitivity of early-flowering families (and the absence of earlyflowering families not sensitive to temperature) may reflect plasticity in flowering time, which may be adaptive in environments where early-season conditions are highly variable among years.

Key words: climate change; first flowering date; global warming; phenology; phenological response; phenological sensitivity.

\begin{abstract}
${ }^{1}$ Manuscript received 31 August 2012; revision accepted 5 February 2013.

We are indebted to those who contributed the phenological time series analyzed here, including the many scientists and volunteers who recorded field data or who managed subsets of the data, particularly A. H. Fitter, R. S. R. Fitter (Chinnor), David Inouye (Gothic), John O'Keefe (Harvard Forest), and Paul Huth, Shana Smiley, and John Thompson (Mohonk, NY). The observational studies examined here were originally designed by investigators and supported by funding sources listed in the online Supplemental Data (Appendix S1). Special thanks are due to the National Center for Ecological Analysis and Synthesis (funded by NSF EF-0553768, the University of California, Santa Barbara, and the State of California) for supporting the working group on "Forecasting Phenology". The Stellenbosch Institute for Advanced Study graciously hosted S.J.M. during the preparation of this manuscript.

${ }^{13}$ Author for correspondence (e-mail: mazer@lifesci.ucsb.edu), phone: +1-805-893-8011
\end{abstract}

doi:10.3732/ajb.1200455
Plant phenology encompasses the timing of seasonal life cycle events, including the onset and duration of vegetative and reproductive phases such as bud break, leaf expansion, flowering, pollen release, and fruit ripening. Interannual variation in the phenology of an individual or population is typically interpreted as reflecting variation in the annual timing of environmental cues, such as the start of spring. Interest in phenology has heightened recently because climate change is predicted to change the annual timing of the cues that initiate phenological transitions (e.g., from winter dormancy to springtime growth), with possible repercussions for plant fitness and ecosystem function.

The timing of each phenophase relative to seasonal variation in temperature, precipitation, frost events, and soil moisture may influence both its duration and its intensity (e.g., the total number of flowers produced), affecting the amount of plant resources available to support primary consumers. In addition, the timing of an individual plant's phenophases relative to that of 
its mutualists and antagonists influences its exposure to competitors, herbivores, diseases, pollinators, seed predators, and fruit dispersers. Consequently, the phenological schedules of individual plants can have strong fitness consequences both for plants and for the animals that depend on them (Harrington et al., 1999; Gordo and Sanz, 2005; Durant et al., 2007; Bertin, 2008; Doi et al., 2008; Hegland et al., 2009; Forrest and Miller-Rushing, 2010; Aldridge et al., 2011; Gilman et al., 2011). For decades, these observations have been well known to evolutionary ecologists studying species interactions. What has only recently become clear is that the degree to which interacting taxa fail to alter synchronously the timing of their phenophases in response to climate change can also have profound effects on individual fitness and population persistence (Both and Visser, 2001; Strode, 2003; Winder and Schindler, 2004; Gordo and Sanz, 2005; Visser and Both, 2005; Both et al., 2006; Hegland et al., 2009; Jones and Cresswell, 2010; Burger et al., 2012; McKinney et al., 2012).

Within and among individual populations and species, the timing of any phenological event may be both environmentally and genetically determined. For example, the first flowering date (FFD) of individual plants is strongly influenced by abiotic conditions, as revealed in many long-term observational studies (reviewed by Bertin, 2008). Populations of many wild taxa also retain significant genetically based variation in FFD (Mazer, 1987; Mazer and Lebuhn, 1999; Leon et al., 2001; Franks and Weis, 2008; Franks, 2011; Kawai and Kudo, 2011; Brunet and Larson-Rabin, 2012), in spite of widespread evidence of strong selection on this trait (Schemske, 1977; Munguía-Rosas et al., 2011), which might be expected to purge genetic variation. In addition, populations clearly respond to natural selection on FFD, which would not occur without a strong heritable component to FFD (Franks et al., 2007; Franks and Weis, 2008; Franks, 2011). Genetic variation in FFD is also common among populations, apparently reflecting adaptive differentiation in response to geographic variation in biotic and abiotic conditions (Mazer and Lebuhn, 1999; Olsson and Ågren, 2002; Stinchcombe et al., 2004; Kawai and Kudo, 2011).

Genetically based variation in FFD among populations suggests that higher taxa may also be expected to diverge in FFD. In support of this view, predictable flowering sequences among families have been found across plant communities (Kochmer and Handel, 1986; Willis et al., 2008; Davis et al., 2010). In addition, FFD has often evolved in a correlated fashion with other traits that frequently show little variation at the family or genus level, such as pollination mode, fruit type, and fruit size (Bolmgren et al., 2003; Bolmgren and Lönnberg, 2005; Bolmgren and Cowan, 2008), which suggests that FFD too may show low variance at higher taxonomic levels. Analyses that have detected a phylogenetic component to variation in FFD have supported this expectation (Davis et al., 2010). Although the mean FFD differs predictably among taxonomic families, we know little about the genetic or taxonomic basis of phenological responses of FFD to climate and their longterm effects on population or species persistence. There is growing evidence, however, that the tendency to alter FFD in response to seasonal temperature promotes population persistence and abundance and has a significant phylogenetic component to its variation (Willis et al., 2008, 2010; Davis et al., 2010; Cleland et al., 2012). In other words, phenological flexibility in response to year-to-year variation in temperature appears to be an adaptive trait that evolves nonrandomly among higher taxa. If so, then even without long-term phenological observations on a given species, we could predict its phenological response to climate based on its taxonomic affinity.

Many long-term observational studies have been conducted in North America, Europe, Asia, and the neotropics to track interannual variation in the onset of phenological events and its relationship to variation in climate (reviewed in Parmesan and Yohe, 2003; Parmesan, 2006; Bertin, 2008; Cook et al., 2008, 2012a, b; Wolkovich et al., 2012). These studies have measured variation within and among plant communities and among taxa in the magnitude, direction, and environmental correlates of their phenological sensitivity to climate. One goal of these investigations has been to document the effects of interannual variation in climate on the onset and duration of phenological events (e.g., Sparks and Carey, 1995; Chung et al., 2011), and they have detected several patterns.

First, sympatric species differ both in the magnitude and the direction of their sensitivity to climate. Most taxa accelerate the onset of flowering in response to interannual increases in mean annual temperature, but some exhibit no response or delay flowering (Fitter et al., 1995; Bradley et al., 1999; Menzel, 2000; Abu-Asab et al., 2001; Fitter and Fitter 2002; Ahas and Aasa, 2006; Menzel et al., 2006a; Zhang et al., 2007; Amano et al., 2010; Cook et al., 2008, 2012a, b; Gordo and Sanz, 2009, 2010; Beaubien and Hamann, 2011; Wolkovich et al., 2012; see Bertin, 2008 for other examples). Second, early-flowering species often exhibit greater advances and/or higher interannual variation in first flowering date than do the later-flowering (Fitter et al., 1995; Sparks et al., 2000; Fitter and Fitter, 2002; Scheifinger et al., 2002; Dunne et al., 2003; Menzel et al., 2006b; Miller-Rushing et al., 2007; Miller-Rushing and Primack, 2008; Cook et al., 2012b; Wolkovich et al., 2012; but see Miller-Rushing and Inouye, 2009). This pattern may reflect particularly close tracking of winter and/or early spring temperatures by early-flowering taxa combined with greater increases in temperatures in winter/spring relative to summer/fall over the last few decades (Myneni et al., 1997; Ahas, 1999; Roetzer et al., 2000; Cayan et al., 2001; Ahas and Aasa, 2006; Bertin, 2008). In some cases, however, early-flowering species delay FFD with increased autumn warming, potentially because they have not received the vernalization (cumulative chill) necessary to promote early flowering (Fitter et al., 1995; Cook et al., 2012a). In sum, species often appear to integrate recent climatic conditions, and then use a threshold sum of growing degree days (which may include a chilling requirement) as a cue to initiate flowering, often after the risk of frost (in the temperate biome) has passed (Scheifinger et al., 2003; Ho et al., 2006; Cook et al., 2008; Wipf, 2010; but see Chmielewski, et al., 2004; Inouye, 2008).

From these community-level studies, we can now characterize the magnitude and direction of the phenological responses of hundreds of species to warmer temperatures. On average, plant species tend to flower 5-6 d earlier per ${ }^{\circ} \mathrm{C}$ increase in mean annual temperature (Wolkovich et al., 2012). The species-specific long-term records analyzed to date do not, however, allow us to forecast directly the phenological response of species that have not been directly observed. If, however, we could accurately forecast the phenological response of a taxon based on its taxonomic affinities, then we could predict the climate-induced phenological shifts of many taxa that have not been previously studied.

In the present study, we evaluate the viability of forecasting phenological shifts on the basis of family membership. We first examine the relationships between FFD and interannual variation in seasonal temperature and precipitation among hundreds of wild plant species from diverse families at seven temperate zone locations where long-term observational studies have been conducted (Table 1). Previous species-level analyses of these data have demonstrated that phenological shifts between years can in many cases be attributed to climatic factors (e.g., Fitter et al., 1995; Abu-Asab et al., 2001; Fitter and Fitter, 2002; Cook et al., 2008, 2012b; Inouye, 2008; Dunnell and Travers, 2011; 
Diez et al., 2012; Wolkovich et al., 2012). Here, we use each species' response of FFD to interannual variation in both temperature and precipitation to derive new indices of sensitivity for each taxon. We then used these sensitivity values to address the following questions: (1) Across these temperate, seasonal sites, do families differ in their sensitivity to interannual variation in cumulative temperature or precipitation? (2) Is the negative relationship between sensitivity to temperature and mean FFD previously observed among species at individual sites also exhibited among family means across sites? (3) Which families are least phenologically sensitive to seasonal temperature? (4) Do sites differ in the mean sensitivity of their families? The patterns observed are interpreted in light of the role that natural selection on FFD and on phenotypic plasticity of FFD in response to climate may play in mediating adaptive responses to climate change.

\section{MATERIALS AND METHODS}

Long-term observational data sets-Phenological data from seven independently conducted long-term observational studies in diverse temperate zone habitats were compiled into a single data set for analysis (Table 1; see Appendix S1 with the online version of this article for additional information about each site). These habitats included continental tallgrass prairies (Konza Prairie, Kansas, and Fargo, North Dakota); alpine vegetation (Gothic, Colorado); and midlatitude temperate forest and grasslands (Chinnor, UK; Hubbard Brook Experimental Forest, New Hampshire; Mohonk Lake, New York: and Washington, D.C.). Each site's mean annual temperature, precipitation and seasonality are provided in Cook et al. (2012b). At each location, the first flowering dates (FFD) of 18-385 species were observed. The number of years of observations differed among species at each site (Table 1), and the median number of years of observation among species was 8-37 yr per site (Abu-Asab et al., 2001; Wright, 2001; Fitter and Fitter, 2002; Richardson et al., 2006; Cook et al., 2008; Inouye, 2008; Travers et al., 2009; Dunnell and Travers, 2011). At each site, for each species, FFD was recorded based on the day of the year $(1=1$ January, etc.). For horsetails, ferns, and gymnosperms, FFD was recorded as the date of spore or pollen release. The sites included in this study are a subset of the 12 sites that comprise the Network of Ecological and Climatological Timings Across Regions (NECTAR) database described by Cook et al. (2012b; see also Appendix S1). The NECTAR database was created to provide a single repository of records of first leaf date (FLD) and first flowering date (FFD) of a taxonomically diverse set of species for which phenological information had been recorded for eight or more years. Sites included in NECTAR comprise those where climate could be estimated from daily temperature and precipitation values available from the Global Historical Climatology Network (GHCN). For the present study, we included only those NECTAR sites at which FFD was recorded; as described below, some observational series were excluded following inspection of the data. The data sets analyzed here ultimately included a total of 1226 species occurrences representing 119 taxonomic families and 1031 unique species. Twenty-three species occurrences comprised horsetails, ferns, or gymnosperms (Table 1).

Across sites, each family was represented by 1-144 species occurrences, with 26 families represented by a single species at only one site and, at the other extreme, 16 families represented by $\geq 20$ species occurrences across sites (for occurrences of each family, see Appendix S1C).

Temperature and precipitation data-For each year for which climatological records were available from a given site, temperature-based climatic indices were calculated using successive 3-mo intervals beginning in August of the preceding year (e.g., August-October, September-November, OctoberDecember) (Cook et al., 2012b). For each 3-mo window, growing degree days (GDD) were summed as follows: GDD $=\max \left(T_{\text {mean }}-\mathrm{GDD}_{\text {thresh }}, 0\right)$, where $T_{\text {mean }}$ is mean daily temperature and $\mathrm{GDD}_{\text {thresh }}$ is the temperature threshold that had to be exceeded in order for a day to qualify as a GDD (in our case, $0^{\circ} \mathrm{C}$ ). Second, for each year at each site, the daily GDD values were then summed for each 3-mo window: $\mathrm{GDD}_{\text {sum }}$ (in a given $\mathrm{yr}$ ) $=\Sigma \mathrm{GDD}$, where $\mathrm{GDD}_{\text {sum }}(\mathrm{yr})$ is the sum of all GDD values represented by all of the days in a given 3-mo window in a given year. Third, at each site, we standardized each 3-mo window's GDD $_{\text {sum }}$ to a mean of zero and a standard deviation of one across all years monitored at the site, as follows: $Z_{\mathrm{t}}=\left(\mathrm{GDD}_{\text {sum }}-\right.$ mean $\left.\mathrm{GDD}_{\text {sum }}\right) / \mathrm{SD} \mathrm{GDD}_{\text {sum }}$, where mean
$\mathrm{GDD}_{\text {sum }}$ and SD GDD $\mathrm{sum}_{\text {sum }}$ are the mean and standard deviation, respectively, of a given 3-mo window's GDD $_{\text {sum }}$ estimated across all of the years during which phenological monitoring occurred at a given location.

This standardization yielded, for each site and 3-mo interval, a mean $\mathrm{GDD}_{\text {sum }}$ of zero and a standard deviation of one across all years for which data were available, thereby accounting for differences among sites in the duration of the observations (i.e., the number of years, and its potential to influence on the within-site variance among years); differences among sites in the magnitude of interannual variance in temperature; differences among 3-mo intervals (within years) in the mean and variance in $\mathrm{GDD}_{\text {sum }}$; and differences among 3-mo intervals in the variance in $\mathrm{GDD}_{\text {sum }}$ across years (thereby eliminating the effects on the sensitivity estimates of higher interannual variation in temperature in winter or early spring than in late spring or summer). The daily precipitation values recorded during each 3-mo interval at each site were similarly summed and used to calculate standardized precipitation (PPT) values for each site.

We then used these standardized, 3-mo temperature and precipitation sums as independent variables with which to detect each species' sensitivity of FFD to temperature and to precipitation at each of the sites. For each species at each site, and for each 3-mo window, we conducted bivariate linear regressions to examine the relationship (across years) between FFD (as the dependent variable) and either the standardized GDD or the standardized PPT (each regression included either GDD or PPT as the independent variable). At each site, for each species and climate predictor, the 3-mo period for which these regression models yielded the highest $R^{2}$ value was identified; the GDD and PPT sums representing these 3-mo windows were then included in a multiple regression that included GDD, PPT, and the interaction between them. The beta coefficients associated with GDD and PPT resulting from this multiple regression were used as the measure of the sensitivity expressed as the change in FFD (in days) per change of one standard deviation in the standardized $\operatorname{GDD}_{\text {sum }}\left(Z_{t}\right)$. These sensitivities are referred to below as betaGDD and betaPPT, respectively. In these linear regressions, negative beta coefficients indicate earlier FFD in response to higher temperatures or higher precipitation, and positive beta coefficients indicate delayed FFD in response to increases in temperature or precipitation. The higher the absolute value of a taxon's beta coefficient, the greater the sensitivity of FFD to the associated climatic predictor. These sensitivities were calculated in the same way as those used by Cook et al. (2012b) except that Cook et al. included only $\mathrm{GDD}_{\text {sum }}$ (and not $\mathrm{PPT}_{\text {sum }}$ ) in the model used to calculate each species' sensitivity.

The method described for identifying the particular 3-mo window to be used for each climatic variable and species to estimate its phenological sensitivity represented a compromise between selecting a single global predictor that could be used for every taxon and location (e.g., mean annual temperature) and selecting highly species-specific models, which would have made it difficult to compare sensitivities across sites and taxa.

Species-level data set-The species-specific beta values (i.e., sensitivities) for GDD and PPT were used in the analyses below. A few species, for which the multivariate model detected significant interactions $(P<0.01)$ between GDD and PPT, were excluded from the data set, as were two species that were strong outliers among the species at their site with respect to their estimated sensitivities to temperature: Dasiphora fruiticosa (Rosaceae) at Gothic, and Dyssoida papposa (Asteraceae) at Konza Prairie. For example, at Gothic, the betaGDD value for Dasiphora fruticosa was -131.01, while the range for the remaining 77 species was -19.36 to 9.61 (mean $=-7.55+$ SD 3.68). At Konza Prairie, the estimated betaGDD value for Dyssodia papposa was -52.16 , while the range for the remaining 145 species was -18.47 to 12.65 (mean $=-2.84+$ SD 4.72). It is not clear whether these are biologically highly unusual taxa; whether the data for these taxa were unreliable (e.g., due to small sample sizes); or whether there were errors in the original data set. Several species were also excluded because their species' names yielded no family identity in either the Kew or the Angiosperm Phylogeny Group data sets. The resulting data set included 1226 species occurrences (i.e., species $\times$ site combinations) in 119 families across the seven sites (Table 1).

Family-level data sets-At each site, site-specific family means for betaGDD and betaPPT were calculated as the means of the confamilial species' beta coefficients. Subsequent analyses, described next, used subsets of these family mean $\times$ site combinations, depending on whether we wished to exclude families represented only by single species or at only one site. For example, 119 families were monitored across all sites, including families represented by a single species at a single site (yielding 325 family $\times$ site combinations). Only 60 families, however, were monitored at $\geq 3$ sites ( 245 family $\times$ site combinations, with $\geq 1$ species/family/site), and 21 families were present at three or more sites 


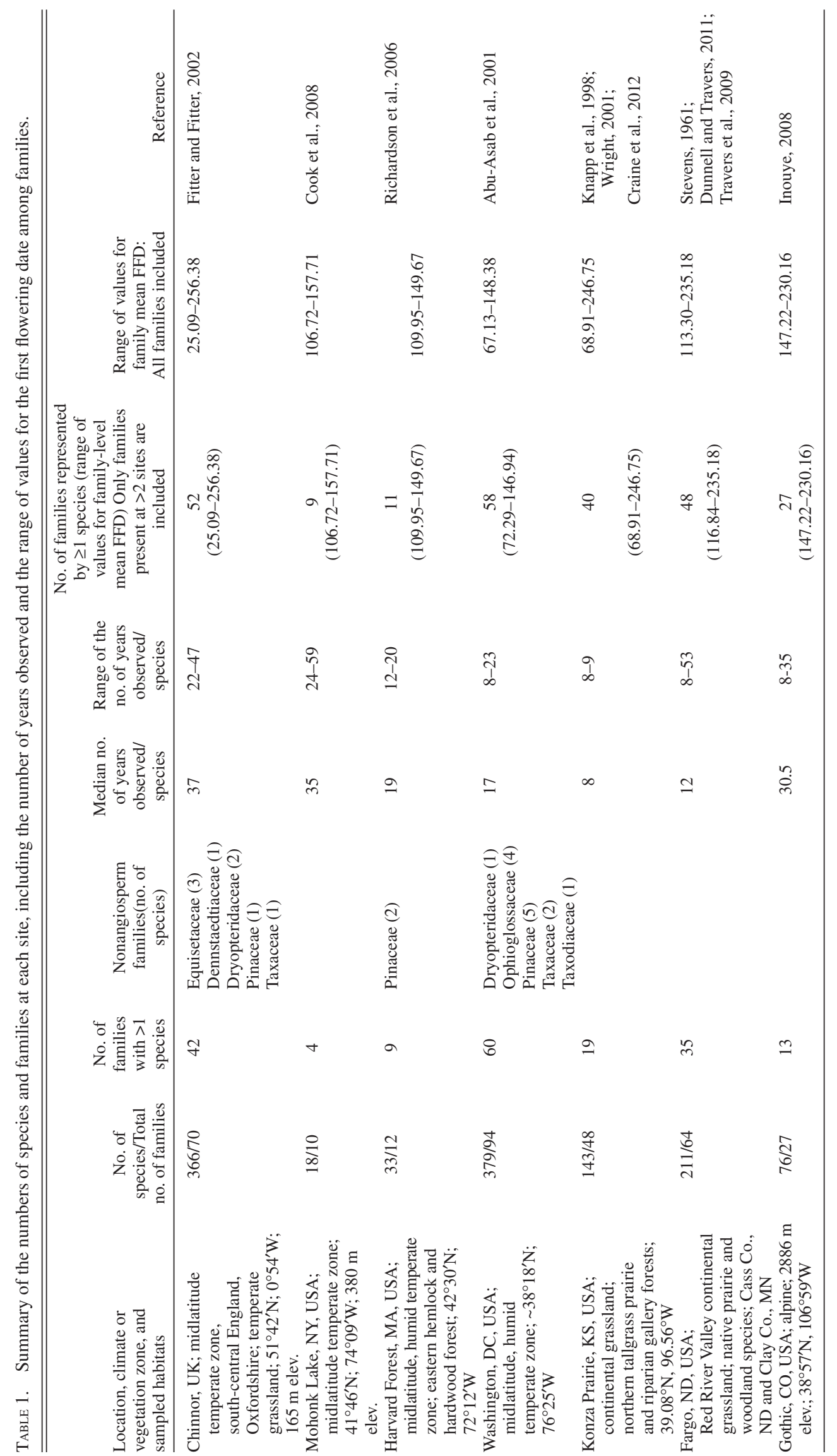


where at least three species per family were present at each site $(83$ family $\times$ site combinations). We estimated family means across sites by averaging site-specific family means.

Analyses-Frequency distributions of beta coefficients (sensitivities of FFD to GDD and PPT)-The distribution of site-specific family means for each variable was subjected to a two-tailed $t$ test to determine whether the mean family-level sensitivities differed significantly from zero.

Standardization of first flowering date-For analyses conducted within sites, the mean FFD of species and families was used. A one-way analysis of variance (ANOVA) detected significant differences among sites with respect to the mean FFD of their species and families (see Results). To remove the effects of this variation among sites when pooling their data for subsequent analyses, we first standardized FFD to a mean of zero and a standard deviation of one at each site by subtracting each species' mean FFD across its phenological time series from the mean FFD (across species) for the site, and then dividing this difference by the standard deviation in FFD for the site. These species-specific standardized FFDs were used to obtain family means within sites, and these sitespecific family means were averaged to estimate each family's mean standardized FFD across sites, expressed in units of standard deviations. To examine the comparability of these two measures of FFD, we used a simple regression to determine the relationship between the mean standardized FFD and the mean raw FFD among the 21 most common and widespread families (see above).

The standardized FFD values measure each taxon's mean FFD relative to the other taxa at the site where it was observed. This parameter therefore statistically eliminates the effects of variation among species, families, and sites in FFD due to differences among sites in the mean and variance of the raw value for FFD. The standardization of FFD is crucial when pooling sites to examine the cross-site relationships among family means between sensitivity and FFD. Without this standardization, a family with a mean raw FFD value of 140 would be a very earlyflowering taxon if observed at Gothic but a very late-flowering taxon if observed at Harvard (Table 1). Using the standardized FFD, the family's relative flowering time is analyzed independently of its raw FFD value. Similar to all standardization procedures that control statistically for variation in factors that affect the variance in the independent variable (including routine residual analyses and the standardization of the climate predictors described above), the standardization of FFD increases the ability of the regressions to detect a statistically significant relationship between temperature- or precipitation-sensitivity and FFD.

Differences among families in standardized FFD, betaGDD, and betaPPTWe conducted two-way fixed factor ANOVAs on each data set described above to detect significant differences among families (across sites) in standardized FFD, betaGDD, and betaPPT. Because the data were unbalanced (many families were absent at many sites), the model was restricted to including family and site (but not the family $\times$ site interaction) as independent factors. Type III sums of squares were used to detect significant main effects (JMP, version 9.0; SAS Institute, Cary, North Carolina, USA).

Analyses of covariance to detect the independent effects of family and FFD on temperature-sensitivity-To determine whether the effects of family on betaGDD detected in the two-way ANOVAs described above were mediated by or independent of the families' standardized FFD, we conducted analyses of covariance (ANCOVA) using betaGDD as the dependent variable and family and standardized FFD as the independent variables. In this model, if the effect of family is statistically significant even when FFD is included in the model, this would mean that taxonomic families differ in their temperature-sensitivity independently of their FFD relative to other taxa at their site. If, however, the effect of family cannot be detected statistically when FFD is included in the model, this would mean that the differences in temperature-sensitivity detected among families are mediated by variation among them in their FFD (or by a factor strongly associated with FFD). These ANCOVAs were conducted on the data sets that were sufficiently well balanced to permit the analysis.

Relationships between sensitivity to climatic predictors and FFD-Bivariate regressions of betaGDD or betaPPT vs. standardized (or raw) FFD were conducted at the species and family levels. To reduce the statistical effects of single families that were geographically restricted and/or rare in the data set, we repeated some analyses on the more restricted data sets ( $N=60$ or $N=21$ families). First, bivariate regressions of betaGDD and betaPPT on standardized FFD among the 1226 species occurrences distributed across and within sites were conducted. Second, regressions of mean betaGDD and betaPTT on mean standardized FFD among the 60 families represented by $\geq 1$ species at $\geq 3$ sites were conducted. Third, mean betaGDD and mean betaPTT were each regressed on, separately, the mean FFD and the mean standardized FFD among 21 family means, where every site $\times$ family combination included $\geq 3$ species. Fourth, all species occurrences in each of the 10 most common families were examined to determine whether the relationships among taxa between betaGDD or betaPTT and the standardized FFD were consistent across families. Within each of these families, some species contributed multiple data points because they were represented at multiple sites (where their betaGDD and betaPPT values were independently measured), but this did not drastically increase the degrees of freedom in each analysis (see Results).

\section{RESULTS}

Distribution of family-level sensitivities to GDD and PPT within sites-Most (or all) families at most sites advanced flowering in response to increasing seasonal warmth; most betaGDD values are $<0$, and the mean betaGDD among families is significantly $<0$ at all sites (Fig. 1, Table 2). At five of the seven sites, a few families delayed flowering (betaGDD $>0$ ) in response to increasing temperatures. By contrast, the family means for betaPPT indicate much lower mean sensitivity to standardized increases in precipitation (Fig. 1). Only three of seven sites (Mohonk, Chinnor, and Gothic) exhibit a mean betaPPT among family means that is significantly different from zero. At these sites, the mean betaPPT values are significantly $>0$; increasing precipitation at these sites resulted, on average, in a delay in FFD (Table 2).

FFD vs. standardized FFD across sites-Among the 21 most evenly distributed families, the mean raw and standardized FFDs are highly correlated (Fig. 2). The few relatively large deviations of standardized FFD from the predicted values indicate cases where families are found in two or more habitats that differ greatly in the distributions of their raw FFDs. Using the standardized FFDs controls for variation among sites in the mean and range of their raw FFDs.

Differences among sites in mean FFD_Sites differed significantly in mean FFD, whether species or family means for FFD were used (one-way ANOVA: effect of site on species mean FFD: $F_{6,1225}=86.09, P<0.0001, R^{2}=0.30$; effect of site on family mean FFD, using the family means from all 119 families: $F_{6,324}=25.46, P<0.0001, R^{2}=0.32$ ). Washington, D.C. exhibited the earliest mean FFD, while Gothic exhibited the latest mean FFD. At each site, the mean FFD remained unchanged regardless of whether species' or family mean values for FFD were used (Table 3: the correlation among site means based on species- vs. family-level FFDs is highly significant and positive $(r=0.98, P<0.0002$, df $=6)$. So, although some families were represented by many more species than others (see Appendix S1C), this imbalance did not affect the site means for FFD.

Among sites, the standard deviation (SD) in the FFD among species and among family means varies by a factor of four. These differences among sites in both the mean and variance of FFD justified the standardization of FFD (for use in cross-site analyses, as described above) so that each site had a mean of zero and a SD of one.

Differences among sites in the mean sensitivity of their taxa to temperature or precipitation-There were significant differences among sites in both mean betaGDD and mean betaPPT of the families present (based on the means of 119 families; Table 3) 

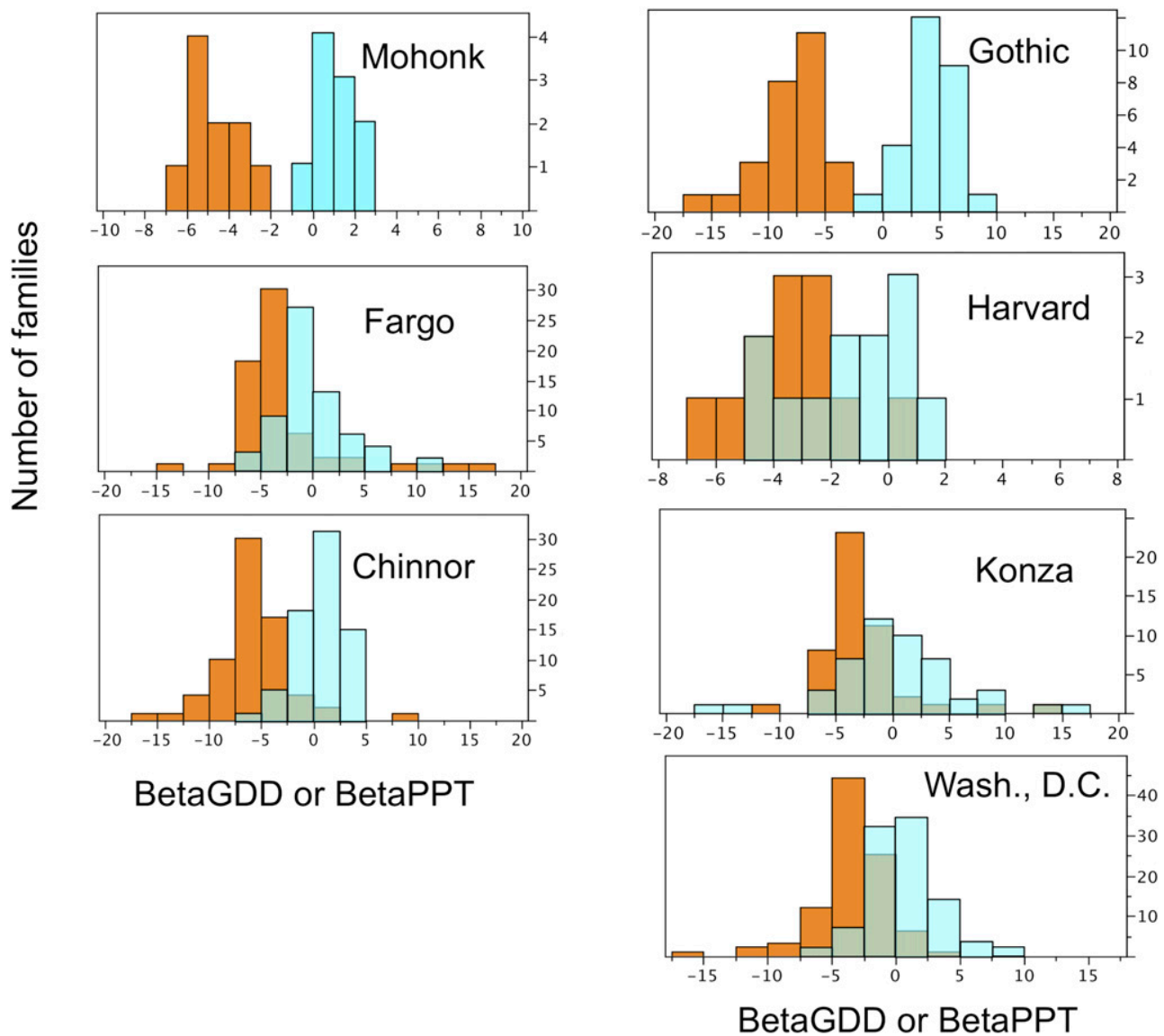

Fig. 1. Frequency distributions of mean sensitivity to temperature (betaGDD) (orange) and sensitivity to precipitation (betaPTT) (blue) among family means at each site. At each site, each family's mean betaGDD and betaPTT were estimated from the values of the confamilial species. Shaded areas indicate where the distributions overlap.

(one-way ANOVAs: Effect of site on family mean betaGDD: $F_{6,324}=9.76, P<0.0001, R^{2}=0.16$; Effect of site on family mean betaPPT: $\left.F_{6,324}=5.33, P<0.0001, R^{2}=0.09\right)$. The relatively low $R^{2}$ values of these models, however, indicate that there was much more variation among families in sensitivity to temperature and precipitation than can be accounted for by sitespecific conditions.

Family means at Gothic exhibited the highest absolute sensitivity to both temperature and precipitation. On average, families at Gothic advanced FFD by 7.9 d per standardized increase in GDD and delayed FFD by $3.8 \mathrm{~d}$ per standardized increase in PPT (likely the result of increased snowpack). By contrast, families at Konza Prairie advanced FFD by only $2.8 \mathrm{~d}$ in response to temperature, and families at Fargo exhibited no change in FFD in response to precipitation (mean betaPPT $=-0.005$ ).

Differences among families in standardized FFD-Twoway ANOVAS detected highly significant variation among family means, across sites, in the standardized FFD, regardless of the data set analyzed (Table 4A-E; for the 10 most common families, see Fig. 3).

Differences among families in betaGDD_-Two-way ANOVAs consistently detected significant variation among family means

TABLE 2. Summary of mean family sensitivities of first flowering day (FFD) to growing degree days and to total precipitation; sensitivities are reported as sensitivity to temperature (betaGDD) and betaPPT, the beta-coefficients for the regressions of FFD on standardized GDD and PPT values, respectively. Twotailed $t$ tests and signed rank tests were conducted to detect whether the mean family-level sensitivity at each site was significantly different from zero.

\begin{tabular}{|c|c|c|c|c|c|c|}
\hline $\begin{array}{l}\text { Site }(N=\text { number } \\
\text { of families })\end{array}$ & $\begin{array}{c}\text { Family mean } \\
\text { betaGDD }<\text { or }>0 ?\end{array}$ & $\begin{array}{c}t \text { test, } \\
\text { test statistic }\end{array}$ & $\begin{array}{c}\text { Probability }> \\
|t|, \text { two-tailed } t \text { test }\end{array}$ & $\begin{array}{c}\text { Family mean } \\
\text { betaPPT }<\text { or }>0 \text { ? }\end{array}$ & $\begin{array}{c}t \text { test } \\
\text { test statistic }\end{array}$ & $\begin{array}{l}\text { Probability }>|t|, \\
\text { two-tailed } t \text { test }\end{array}$ \\
\hline Chinnor (70) & $<0$ & -13.18 & $<0.0001$ & $>0$ & 2.80 & $<0.0067$ \\
\hline Mohonk (10) & $<0$ & -13.11 & $<0.0001$ & $>0$ & 3.58 & 0.0059 \\
\hline Harvard Forest (12) & $<0$ & -6.72 & $<0.0001$ & 0 & -2.11 & 0.0585 \\
\hline Washington, DC (94) & $<0$ & -11.45 & $<0.0001$ & 0 & 2.13 & 0.0356 \\
\hline Konza Prairie (48) & $<0$ & -5.47 & $<0.0001$ & 0 & 0.30 & 0.7645 \\
\hline Fargo (64) & $<0$ & -5.02 & $<0.0001$ & 0 & -0.01 & 0.9890 \\
\hline Gothic (27) & $<0$ & -14.92 & $<0.0001$ & $>0$ & 8.68 & $<0.0001$ \\
\hline
\end{tabular}




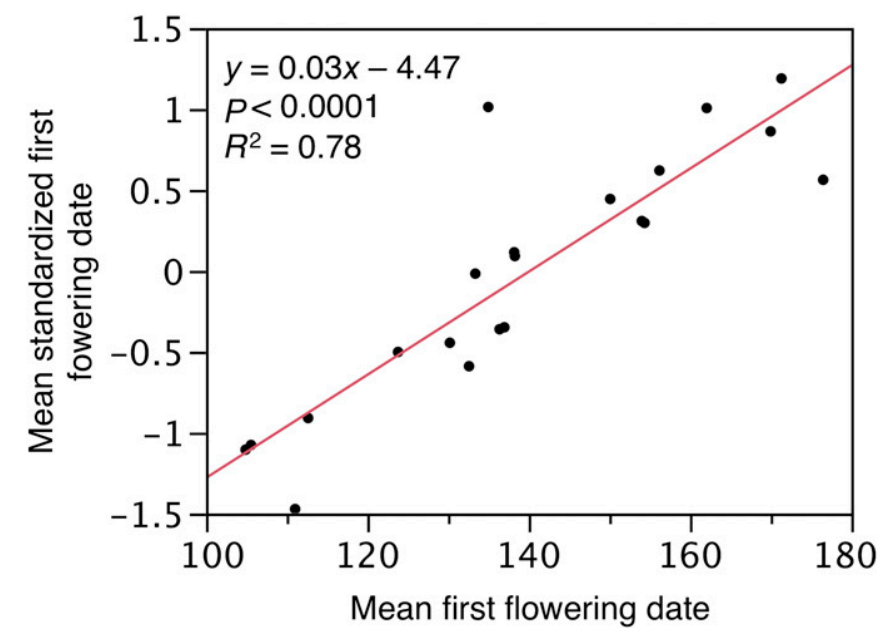

Fig. 2. Relationship between standardized vs. raw first flowering day (FFD) among 21 families distributed across all seven sites. Each family was represented by $\geq 3$ species at each of $\geq 3$ sites (every site $\times$ family combination $\geq 3$ species). Although sites differed significantly with respect to the mean FFD of their species and families (Table 3), the values of FFD standardized for each site to a mean of zero and a standard deviation of one were highly correlated with the raw values of FFD.

in temperature-sensitivity independently of the effects of site, but the strength of the family effect differed among data sets (Table 4A-E). The strongest family effects were detected in data sets that included site-specific family means (Table 4B-D); the weakest statistical effects of family affinity were detected in the data sets composed of individual species' values (Table 4A, E). The mean values of the betaGDD of the 10 best-represented families show that, although the standard errors of the most extreme family means for FFD and betaGDD do not overlap (Fig. 3; Fabaceae and Poaceae vs. Brassicaceae, Lamiaceae, Ranunculaceae, and Rosaceae), the ANOVA did not detect a significant family effect on temperature-sensitivity when applied to the individual species values (Table 4E).

Differences among families in betaPPT - Two-way ANOVAs detected significant variation among families only in the data set comprising the 119 site-specific family means (Table 4B).

Analyses of covariance to detect the independent effects of family and FFD on temperature-sensitivity-None of the ANCOVAs detected a significant effect of family on betaGDD independently of the families' standardized FFDs (Table 5).
The effect of FFD on betaGDD, however, was statistically significant in all tests based on site-specific family means.

Relationships between sensitivities and standardized FFDRelationships among species across pooled sites-The regression of betaGDD on the standardized FFD was significantly positive; species that flowered early relative to the mean FFD of co-occurring species showed more negative betaGDD values than late-flowering species (Fig. 4). Of the 1226 phenological series, 1088 had betaGDD $<0 ; 89 \%$ of them exhibited earlier FFDs in response to warmer temperatures. Moreover, the regression illustrates that early-flowering species advanced their flowering in response to a standardized increase in GDD to a greater degree than late-flowering species (see also Wolkovich et al., 2012). The comparable relationship between betaPPT and the standardized FFD was not statistically significant $\left(R^{2}=0, P>\right.$ $0.6278, \mathrm{df}=1225)$.

Relationships among species within sites-Among species, the site-specific relationships between betaGDD and FFD agree with the cross-site relationships. All seven sites exhibit a positive regression slope, although in only four (Chinnor, Fargo, Gothic, and Washington, DC) are the slopes significantly $>0$ (Fig. 5; at Mohonk, $P<0.09$ ). The relationships between betaGDD and the standardized FFD are qualitatively identical, although the regression parameters differ due to the standardization of the $x$-axis (see Appendix S1A). The comparable analyses for betaPPT indicate that three sites exhibit a significant relationship between betaPPT and FFD, but the slope is $>0$ at 1 site (Chinnor), and $<0$ at two sites (Konza Prairie, KS and Washington, D.C.) (see Appendix S1B).

Relationships among species within families-The relationships between temperature-sensitivity and standardized FFD observed within families mirrors the relationships observed within sites. Within seven of the 10 most common families, earlier-flowering taxa have significantly more negative betaGDD values than later-flowering taxa (betaGDD varies positively with standardized FFD; Table 6). The vast majority of species in each family have betaGDD values $<0$ (Table 6), so these regressions indicate that earlier-flowering confamilial species advance their FFD more than the late-flowering ones. In all families, the mean betaGDD is $<0$ (Appendix S1E). In two of the 10 most common families (Poaceae and Ranunculaceae), betaPTT is negatively associated with standardized FFD (Table 6); in these families, early-flowering taxa have higher betaPTT values than late-flowering taxa do, indicating that the former accelerated flowering less or delay flowering more in response to higher precipitation.

TABLE 3. Site means: the mean values (and standard deviations) for first flowering day (FFD) exhibited by the species and families at each site. Site means of FFD based on species and on families are highly correlated $(r=0.98, N=7)$. Within columns, shared superscripts indicate that means do not differ significantly based on a Tukey's test following a one-way ANOVA.

\begin{tabular}{lcccc}
\hline \hline Site (number of families) & $\begin{array}{c}\text { Mean (SD) FFD } \\
\text { among species }\end{array}$ & $\begin{array}{c}\text { Mean (SD) FFD } \\
\text { among family means }\end{array}$ & $\begin{array}{c}\text { Mean (SD) of betaGDD } \\
\text { among families }\end{array}$ & $\begin{array}{c}\text { Mean (SD) of betaPPT } \\
\text { among families }\end{array}$ \\
\hline Chinnor (70) & $146.19(40.34)^{\mathrm{cd}}$ & $139.16(41.39)^{\mathrm{c}}$ & $-5.59(3.41)^{\mathrm{bc}}$ & $0.70(2.10)^{\mathrm{b}}$ \\
Mohonk (10) & $127.33(19.80)^{\mathrm{de}}$ & $123.69(14.67)^{\mathrm{cd}}$ & $-4.80(1.16)^{\mathrm{abc}}$ & $1.09(0.9)^{\mathrm{ab}}$ \\
Harvard (12) & $123.73(10.33)^{\mathrm{e}}$ & $123.87(9.80)^{\mathrm{cd}}$ & $-3.31(1.71)^{\mathrm{ab}}$ & $-1.31(2.16)^{\mathrm{b}}$ \\
Washington, DC (94) & $112.19(23.78)^{\mathrm{e}}$ & $115.40(19.78)^{\mathrm{d}}$ & $-3.45(2.93)^{\mathrm{a}}$ & $0.59(2.67)^{\mathrm{b}}$ \\
Konza Prairie (48) & $154.14(42.31)^{\mathrm{bc}}$ & $141.63(34.01)^{\mathrm{bc}}$ & $-2.83(3.59)^{\mathrm{a}}$ & $-3.12(4.98)^{\mathrm{a}}$ \\
Fargo (64) & $156.37(27.30)^{\mathrm{b}}$ & $154.55(21.32)^{\mathrm{b}}$ & $-7.92(2.76)^{\mathrm{c}}$ & $-0.005(3.62)^{\mathrm{b}}$ \\
Gothic (27) & $181.65(21.70)^{\mathrm{a}}$ & $181.07(20.48)^{\mathrm{a}}$ & & $3.82(2.29)^{\mathrm{a}}$ \\
\hline
\end{tabular}


TABLE 4. Summary of two-way ANOVAs to detect significant differences among families and sites in standardized first flowering day (FFD) and sensitivity to temperature (betaGDD) or to precipitation (betaPTT). (A) Species values were used in this analysis $(N=1226$ species occurrences). (B) Sitespecific family means of 119 families $(N=325$ family $\times$ site combinations were used in this analysis. (C) Site-specific family means of 60 families present at $\geq 3$ sites were used in this analysis ( $N=245$ family $\times$ site combinations). (D) Site-specific family means of 21 families present at $\geq 3$ sites, each with $\geq 3$ species per family, were used in this analysis $(N=83$ family $\times$ site combinations. (E) Species values were used in this analysis, but only the 10 best-represented families were included $(N=590$ species occurrences across sites).

\begin{tabular}{|c|c|c|c|c|c|c|c|c|c|c|c|}
\hline \multirow[b]{2}{*}{ Source } & \multirow[b]{2}{*}{ df } & \multicolumn{3}{|c|}{ Standardized FFD } & \multicolumn{3}{|c|}{ betaGDD } & \multirow[b]{2}{*}{ Df } & \multicolumn{3}{|c|}{ betaPPT } \\
\hline & & SS & $F$-ratio & $P$-value & SS & $F$-ratio & $P$-value & & SS & $F$-ratio & $P$-value \\
\hline \multicolumn{12}{|c|}{ (A) Species level ( $N=1226$ species occurrences) } \\
\hline Family & 118 & 434.20 & 5.16 & $<0.0001$ & 2718.53 & 1.20 & 0.0785 & & & & \\
\hline Site & 6 & 11.62 & 2.72 & 0.0126 & 1746.09 & 15.18 & $<0.0001$ & & & & \\
\hline Model & 124 & 434.20 & 4.91 & $<0.0001$ & 4747.64 & 2.00 & $<0.0001$ & & & & \\
\hline Error & 1101 & 784.80 & & & 21095.68 & & & & & & \\
\hline Corrected total & 1225 & 1219.00 & & & 25843.32 & & & & & & \\
\hline$R^{2}$ & 0.36 & & & & 0.18 & & & & & & \\
\hline \multicolumn{12}{|c|}{ (B) Family means ( $N=119$ families $)$} \\
\hline Family & 118 & 152.40 & 2.83 & $<0.0001$ & 1815.75 & 1.40 & 0.0182 & 118 & 1763.17 & 1.69 & 0.0006 \\
\hline Site & 6 & 7.55 & 2.75 & 0.0136 & 607.00 & 9.22 & $<0.0001$ & 6 & 273.87 & 5.16 & $<0.0001$ \\
\hline Model & 124 & 159.80 & 2.82 & $<0.0001$ & 2554.78 & 1.88 & $<0.0001$ & 124 & 2118.64 & 1.93 & $<0.0001$ \\
\hline Error & 200 & 91.35 & & & 2195.68 & & & 200 & 1770.35 & & \\
\hline Corrected total & 324 & 251.15 & & & 4750.46 & & & 324 & 3889.00 & & \\
\hline$R^{2}$ & 0.64 & & & & 0.54 & & & 0.54 & & & \\
\hline \multicolumn{12}{|c|}{ (C) Family means ( $N=60$ families $)$} \\
\hline Family & 59 & 134.03 & 3.91 & $<0.0001$ & 840.64 & 1.46 & 0.0309 & & & & \\
\hline Site & 6 & 1.17 & 0.34 & 0.9175 & 590.51 & 10.08 & $<0.0001$ & & & & \\
\hline Model & 65 & 134.04 & 3.55 & $<0.0001$ & 1512.52 & 2.38 & $<0.0001$ & & & & \\
\hline Error & 179 & 103.96 & & & 1746.94 & & & & & & \\
\hline Corrected total & 244 & 238.00 & & & 3259.46 & & & & & & \\
\hline$R^{2}$ & 0.56 & & & & 0.46 & & & & & & \\
\hline \multicolumn{12}{|c|}{ (D) Family means ( $N=21$ families $)$} \\
\hline Family & 20 & 38.31 & 7.67 & $<0.0001$ & 217.56 & 2.01 & 0.0212 & & & & \\
\hline Site & 6 & 2.62 & 1.75 & 0.1272 & 155.43 & 4.79 & 0.0005 & & & & \\
\hline Model & 26 & 44.59 & 6.87 & $<0.0001$ & 388.80 & 2.76 & 0.0007 & & & & \\
\hline Error & 56 & 13.98 & & & 303.12 & & & & & & \\
\hline Corrected total & 82 & 58.58 & & & 691.92 & & & & & & \\
\hline$R^{2}$ & 0.76 & & & & 0.56 & & & & & & \\
\hline \multicolumn{12}{|c|}{ (E) Species values ( $N=10$ families, 590 species occurrences) } \\
\hline Family & 9 & 108.04 & 14.68 & $<0.0001$ & 152.95 & 0.83 & 0.5916 & & & & \\
\hline Site & 6 & 6.74 & 1.37 & 0.2229 & 842.12 & 6.83 & $<0.0001$ & & & & \\
\hline Model & 15 & 120.62 & 9.83 & $<0.0001$ & 1013.38 & 3.29 & $<0.0001$ & & & & \\
\hline Error & 574 & 469.43 & & & 11799.28 & & & & & & \\
\hline Corrected total & 589 & 590.04 & & & 12812.65 & & & & & & \\
\hline$R^{2}$ & 0.20 & & & & 0.08 & & & & & & \\
\hline
\end{tabular}

Relationships among family means across sites-The relationships between temperature-sensitivity and standardized FFD observed among families across sites mirrors the relationships observed within sites. Early-flowering families were more sensitive to temperature, and advanced their mean FFDs in response to warmer temperatures to a greater extent than, lateflowering families. Among the 60 families recorded at three or more sites, 59 exhibited mean betaGDD values that were less than zero, and the families that flowered consistently early (relative to each site's mean FFD) had significantly lower (more negative) betaGDD values than late-flowering families (Fig. 6). This regression remained significant (and the slope positive) even when the outlier (the Commelinaceae) was excluded ( $y=$ $0.99 x-4.49 ; R^{2}=0.1, P<0.0012, N=59$ ).

The positive relationship between betaGDD and FFD is also observed among the 21 families represented by three or more species at three or more sites (Fig. 7) for both the raw and the standardized FFD, with a notable increase in the $R^{2}$ value relative to the 60 -family regression. Removal of the outlier (the Onagraceae) does not qualitatively change the results (for betaGDD vs. mean FFD: $y=0.03 x-9.13, R^{2}=0.29$, $P<0.0141, N=20$; for betaGDD vs. mean standardized FFD: $\left.y=1.08 x-4.72, R^{2}=0.47, P<0.0009, N=20\right)$. None of the comparable analyses of betaPTT are statistically significant. Family means for FFD, standardized FFD, and betaGDD are shown in Appendix S1D.

Relationships among family means within sites-Four of the seven sites had a significantly positive relationship between betaGDD and FFD (Fig. 8); at these sites, including families represented by only one species, families that flowered early had greater advances than later-flowering families in FFD in response to high GDD. Moreover, only late-flowering families had positive betaGDD values, indicating delays in FFD in response to warmer temperature. The three sites that did not exhibit statistically significant relationships also show positive trend lines (data not shown), similar to the species-level analyses of these sites (Fig. 5).

Only one site (Fargo) exhibited a significant relationship between betaPTT and FFD (Fig. 9A); families that flowered early are more likely to advance their flowering or to delay it less in response to higher PTT than late-flowering families. Fargo was also the only site at which a large proportion of the families and species had betaPPT values $>0$. The significant positive 


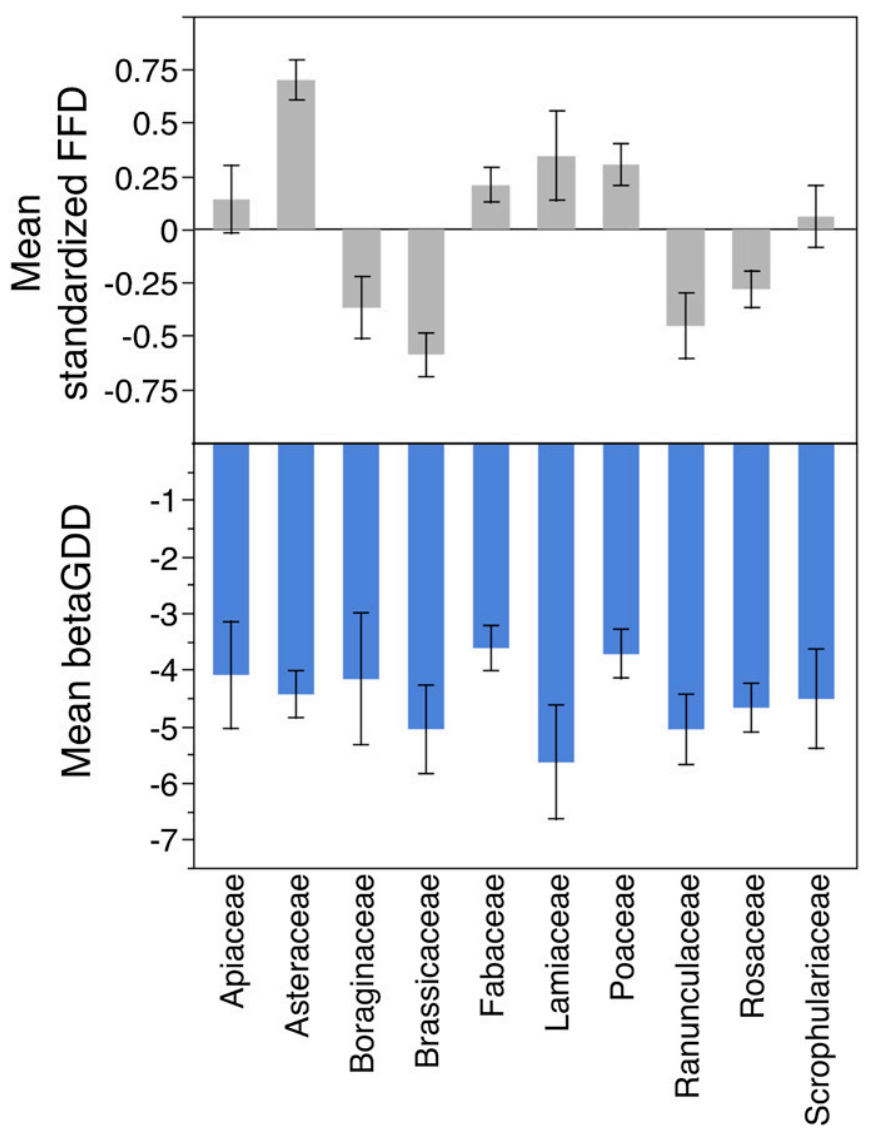

Fig. 3. Family means of the 10 best-represented families across sites. Families differed significantly with respect to their standardized first flowering day (FFD), but statistically significant differences among families in sensitivity to temperature (betaGDD) were detected only in the data sets that comprised $>10$ families (Table 4 ).

relationship between betaPTT and FFD pattern is not observed among species at Fargo in spite of the higher degrees of freedom in the species-level regression (Fig. 9B).

\section{DISCUSSION}

Among families, within and across sites, we detected two features of temperature-sensitivity that are similar to those previously reported among species within sites. First, as for species, there is significant variation among families with respect to both the magnitude and the direction of their phenological responses to increases in seasonal temperature. Second, earlyflowering families generally exhibit greater advances in first flowering date in response to warmer temperatures than late-flowering families, although the $R^{2}$ values of the models that detect this relationship are often low (range: 0.08-0.39; Figs. 6-8). Many other long-term observational studies have also detected this relationship, but see the contribution of Iler et al. (2013) in this special issue for a counter-example at an arctic tundra site. Consequently, while one may qualitatively predict the type of phenological response that a species will exhibit based on the mean relative FFD of its family, the quantitative accuracy of such predictions may be quite low. Several species-level analyses have found that some early-flowering species delay their first
TABLE 5. Analyses of covariance to detect the effects of family on temperature-sensitivity independent of standardized first flowering day (FFD). Data sets as described in Table 4.

\begin{tabular}{|c|c|c|c|c|}
\hline \multirow[b]{2}{*}{ Source } & \multicolumn{4}{|c|}{ Sensitivity to temperature (betaGDD) } \\
\hline & df & SS & $F$-ratio & $P$-value \\
\hline \multicolumn{5}{|c|}{ (A) Species level ( $N=1226$ species occurrences) } \\
\hline Family & 118 & 2814.15 & 1.14 & 0.1494 \\
\hline Standardized FFD & 1 & 23.87 & 1.15 & 0.2847 \\
\hline Model & 119 & 2819.12 & 1.14 & 0.1606 \\
\hline Error & 1106 & 23048.88 & & \\
\hline Corrected total & 1225 & 25867.99 & & \\
\hline$R^{2}$ & 0.11 & & & \\
\hline \multicolumn{5}{|c|}{ (B) Family means ( $N=119$ families; $N=325$ species) } \\
\hline Family & 118 & 1673.39 & 1.15 & 0.1911 \\
\hline Standardized FFD & 1 & 274.74 & 22.28 & $<0.0001$ \\
\hline Model & 119 & 2222.53 & 1.51 & 0.0047 \\
\hline Error & 205 & 2527.93 & & \\
\hline Corrected total & 324 & 4750.46 & & \\
\hline$R^{2}$ & 0.47 & & & \\
\hline \multicolumn{5}{|c|}{ (C) Family means ( $N=60$ families; $N=245$ species) } \\
\hline Family & 59 & 748.11 & 1.06 & 0.3811 \\
\hline Standardized FFD & 1 & 131.82 & 11.00 & 0.0011 \\
\hline Model & 60 & 1053.83 & 1.47 & 0.0284 \\
\hline Error & 184 & 2205.63 & & \\
\hline Corrected total & 184 & 3259.46 & & \\
\hline$R^{2}$ & 0.32 & & & \\
\hline \multicolumn{5}{|c|}{ (D) Species values ( $N=10$ families, 590 species occurrences) } \\
\hline Family & 9 & 286.87 & 1.63 & 0.1040 \\
\hline Standardized FFD & 1 & 1301.17 & 66.43 & $<0.0001$ \\
\hline Model & 10 & 1472.43 & 7.52 & $<0.0001$ \\
\hline Error & 579 & 11340.23 & & \\
\hline Corrected total & 589 & 12812.65 & & \\
\hline$R^{2}$ & 0.11 & & & \\
\hline
\end{tabular}

flowering date in response to warmer autumns, perhaps because they have not received sufficient autumn or winter chill to induce flowering. We do not yet know whether this is the case at the family level.

Five aspects of the analyses discussed in the following sections should be considered when interpreting our results or designing future investigations. First, the specific years over which each taxon included in our analyses was observed varied both within and across sites. Other results reported in this issue (Iler et al., 2013) show clearly that the particular window over which observations occur can influence both the direction and the magnitude of phenological responses in response to interannual changes in climate. Phenological responses estimated from short windows may therefore not be representative of longerterm patterns.

Second, we used the same approach for estimating the sensitivity of FFD to precipitation as we did for detecting and estimating the sensitivity to temperature, namely by expressing seasonal precipitation as its sum over a 3-mo period before flowering. It is possible that the effects of precipitation (rain or snow) on the onset of flowering operate over some other time interval, such that the low precipitation-sensitivities that we detected here greatly underestimated the actual responses to soil moisture.

Third, while it is most parsimonious to infer that advances in FFD in response to interannual warming are a direct response to temperature, this association might be mediated by seasonal increases in plant growth and plant size. For example, the onset of flowering may require that plants reach a threshold size or produce a threshold amount of leaf biomass, both of which are likely to be influenced by recent temperatures. While it was 
Sensitivity to temperature vs. standardized FFD among all species occurrences

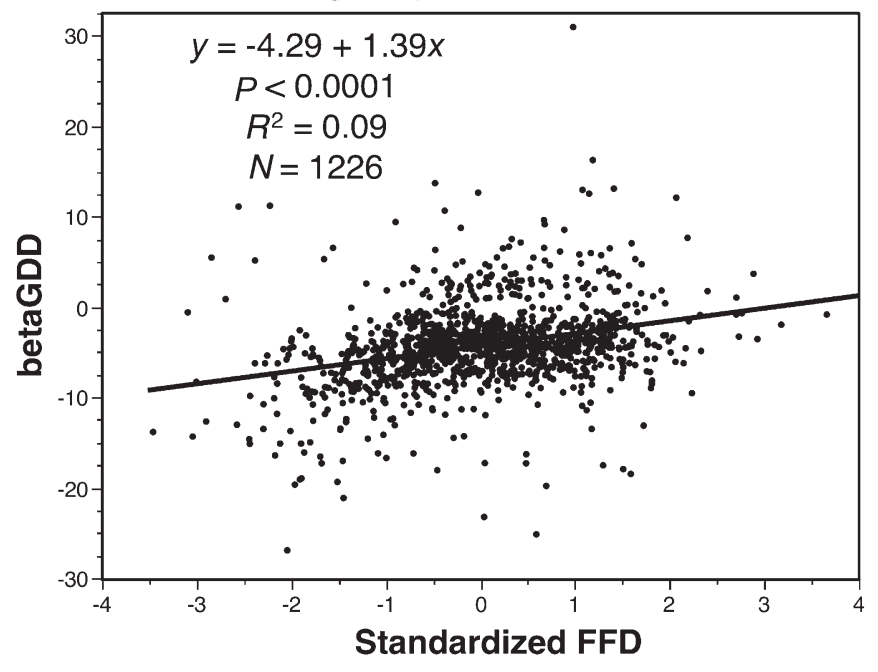

Fig. 4. Relationship between sensitivity to temperature (betaGDD) and standardized first flowering day (FFD) among 1226 species occurrences distributed across all seven sites. Species that flower early relative to the mean FFD of the site where they occur tend to show more negative betaGDD values; they advance flowering in response to higher GDD more than late-flowering species. Of 1226 species, 1088 occurrences exhibit betaGDD $<0$.

beyond the scope of this study to include plant size as a covariate or causal variable influencing FFD independently of seasonal temperatures, examining the relationships among temperature, plant size, and FFD might help to elucidate the mechanisms that contribute to the relationship between temperature and FFD.

Fourth, the analyses reported here assume that the identification of the taxonomic families is correct. We used the most recent taxon names available in the International Plant Names Index (http://www.ipni.org) and the Angiosperm Phylogeny Group's (APG: http://www.mobot.org/MOBOT/research/ APweb/) family identifications, but should these change, the values in our data sets would also be altered. Finally, the 112 angiosperm families (excluding the seven nonangiosperm families reported in Table 1) included in the most inclusive data set examined here represent $27 \%$ of the 413 families identified by the APG; future studies that include a broader range or different subset of families may well reveal different patterns.

Does family membership predict sensitivity to interannual variation in temperature or precipitation across these sites?Taxonomic families differed significantly across sites in the sensitivity of their species' FFD to summed temperature during the 3-mo window before flowering that best accounted for variation in FFD (Table 4B-D). Similarly, the families represented in our data set also differed significantly in betaPPT, the estimated sensitivity of their species' FFD to precipitation during the 3-mo window that best accounted for variation in FFD (Table 4B). The proportion of variance in these sensitivities that was explained by family membership depended strongly, however, on the composition of the data set (i.e., whether the data included families found at only one site or families represented by only one species at a given site).
Why does family membership matter? The link between FFD and phenological sensitivity among families-All analyses detected significant differences among families with respect to their mean standardized FFD (examples in Fig. 4; cf. Davis et al., 2010), which in turn consistently predicted the direction and magnitude of the mean change in FFD in response to standardized increases seasonal temperature (Figs. 7, 8). This pattern mirrors the relationship among species at these sites previously reported by Wolkovich et al. (2012), who estimated specieslevel sensitivities from mean annual temperature (rather than the species-specific 3-mo intervals used here). Here we have shown that the pattern observed among species within sites is mirrored by the pattern observed among family means across sites. The predictive value of these relationships, however, must be considered cautiously as the $R^{2}$ values of these bivariate relationships can be quite low when families are unequally distributed across sites (e.g., Fig. 6).

The phenological response of FFD to temperature of a species for which we have no direct observations can be approximated either by knowing its FFD relative to other co-occurring taxa (which predicts its sensitivity) or by identifying its family (at least among the 119 families evaluated here). The degree of error in this approximation will be, in part, a function of the withinfamily variance (or standard deviation) in FFD and in betaGDD, both of which can be quite high (Appendices S1C, S1D, and S1E with the online version of this article). For example, among the 10 best-represented families examined here, the Fabaceae exhibited the lowest variation among confamilial taxa in the standardized FFD (mean standardized FFD $=0.21, \mathrm{SD}=0.71 ; N=76$ phenological series), and the Lamiaceae exhibited the highest variation (mean standardized $\mathrm{FFD}=0.34, \mathrm{SD}=1.13 ; N=29$ ). The Fabaceae also exhibited the lowest variation among confamilial taxa in the betaGDD (mean betaGDD $=-3.62, \mathrm{SD}=3.39$; $N=76$ ) and the Boraginaceae exhibited the highest variation (mean betaGDD $=-4.17, \mathrm{SD}=6.02 ; N=27$; see online Appendix S1E. The analyses of site-specific family means also indicate that, within sites, family membership can be used to predict the mean temperature-sensitivity of its species (Table 4B-D; Fig. 5), but this relationship is not always statistically detectable (Table $4 \mathrm{~A}, \mathrm{E})$ and must be interpreted cautiously.

The relationships between temperature-sensitivity and FFD observed among family means were also observed among species within the majority of the most diverse and widespread families observed here (Table 6). In seven of 10 families, earlyflowering taxa exhibited significantly greater temperaturesensitivity (more negative betaGDD values) than late-flowering taxa (Table 6). The relationship was in the same direction but not significant in the Fabaceae, Ranunculaceae, or Scrophulariaceae. Exploration of the within-family relationships in other diverse or widespread families (e.g., there were six other families with $\geqq 20$ species occurrences; Appendix S1C) might detect whether families ever differ qualitatively in the relationship between temperature-sensitivity and FFD. Species in late-flowering families might be predicted to exhibit weaker relationships than those in early-flowering families. Families with weak relationships might be comprised of "divergent responders" (Cook et al., 2012a); species that delay flowering in response to warmer falls but advance flowering in response to warmer springs, resulting in little net change in FFD. The comparable relationships between sensitivity to precipitation (betaPTT) and FFD among confamilial taxa were statistically nonsignificant, except in two families (Poaceae and Ranunculaceae) in which a negative relationship was observed (Table 6). 

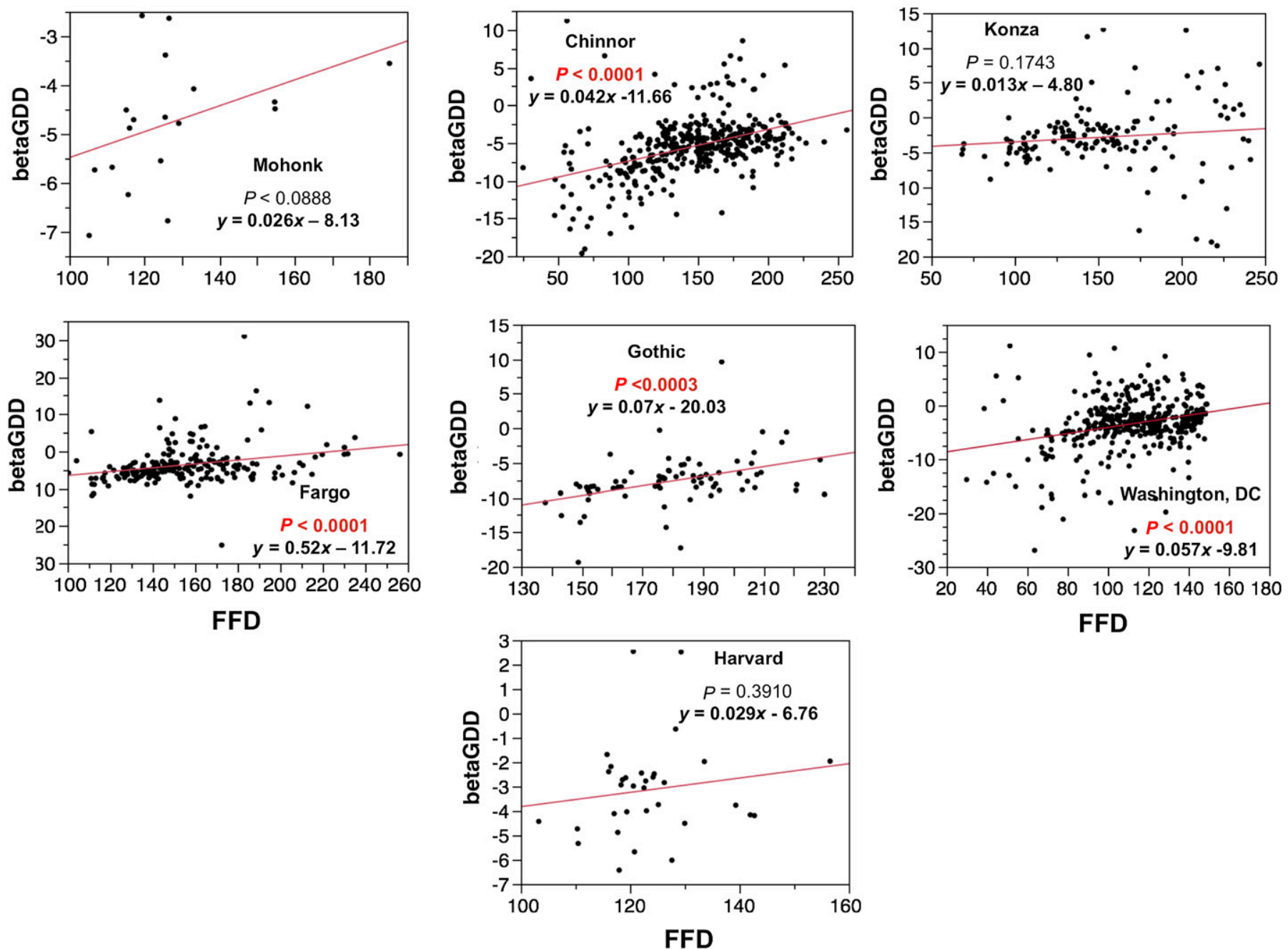

Fig. 5. Relationship between sensitivity to temperature (betaGDD) and first flowering day (FFD) among species at each of seven sites. Four of seven sites exhibit regression slopes significantly greater than zero; trend lines are retained on nonsignificant regressions to illustrate that the relationships are qualitatively similar among all seven sites.

Although we observed high variation among species with respect to sensitivity to seasonal precipitation, the ability to predict the responses of FFD to precipitation from either FFD or family membership was much lower than for temperature sensitivity, perhaps because plants in these habitats are not generally water-limited prior to the initiation of flowering. Moreover, the qualitative relationships between betaPTT and FFD were inconsistent even among the three sites where the relationship was statistically significant ( $>0$ at Chinnor; $<0$ at Konza Prairie and Washington, D.C.; Appendix S1B). In addition, at the one site (Fargo) where mean family FFD was a reliable predictor of mean family sensitivity to precipitation (Fig. 9A), the species-level relationship (Fig. 9B) was statistically very weak in spite of the much higher sample size (64 families vs. 211 species). At this site, the family membership of a taxon permitted a more reliable prediction of its flowering response to recent precipitation than did its species-specific FFD.

Differences among sites in the mean sensitivities of their taxa-The generalization that FFD is more sensitive to warming than to precipitation in seasonal, temperate zone habitats is also reflected in the differences between the site means for betaGDD vs. betaPPT (Table 3). At all sites, the absolute value of the mean of family means for betaGDD exceeds that for betaPPT.

The site means for betaGDD reported here differ slightly from those reported by Cook et al. (2012b) for three reasons. First, Cook et al. (2012b) estimated betaGDD in a model that included only growing degree days as the independent variable, while here we used a model that also included precipitation and the interaction between them. Second, here we used family means (as opposed to individual species' values) to estimate site means, which reduces the influence of highly speciose families with particularly high or low betaGDD values. Third, here we excluded a total of 39 species occurrences from the original data set (i.e., two outliers plus 37 phenological series that exhibited a significant GDD $\times$ PPT interaction when estimating their sensitivities). Nevertheless, the estimates of Cook et al. (2012b) for the site mean betaGDD values are highly correlated with those reported here $(r=0.83, P<0.0222, N=7)$.

The evolutionary significance of the relationships between betaGDD and $F F D$-Early-flowering families had significantly more negative values of betaGDD than late-flowering families, and it was rare to find an early-flowering taxon that delayed its 


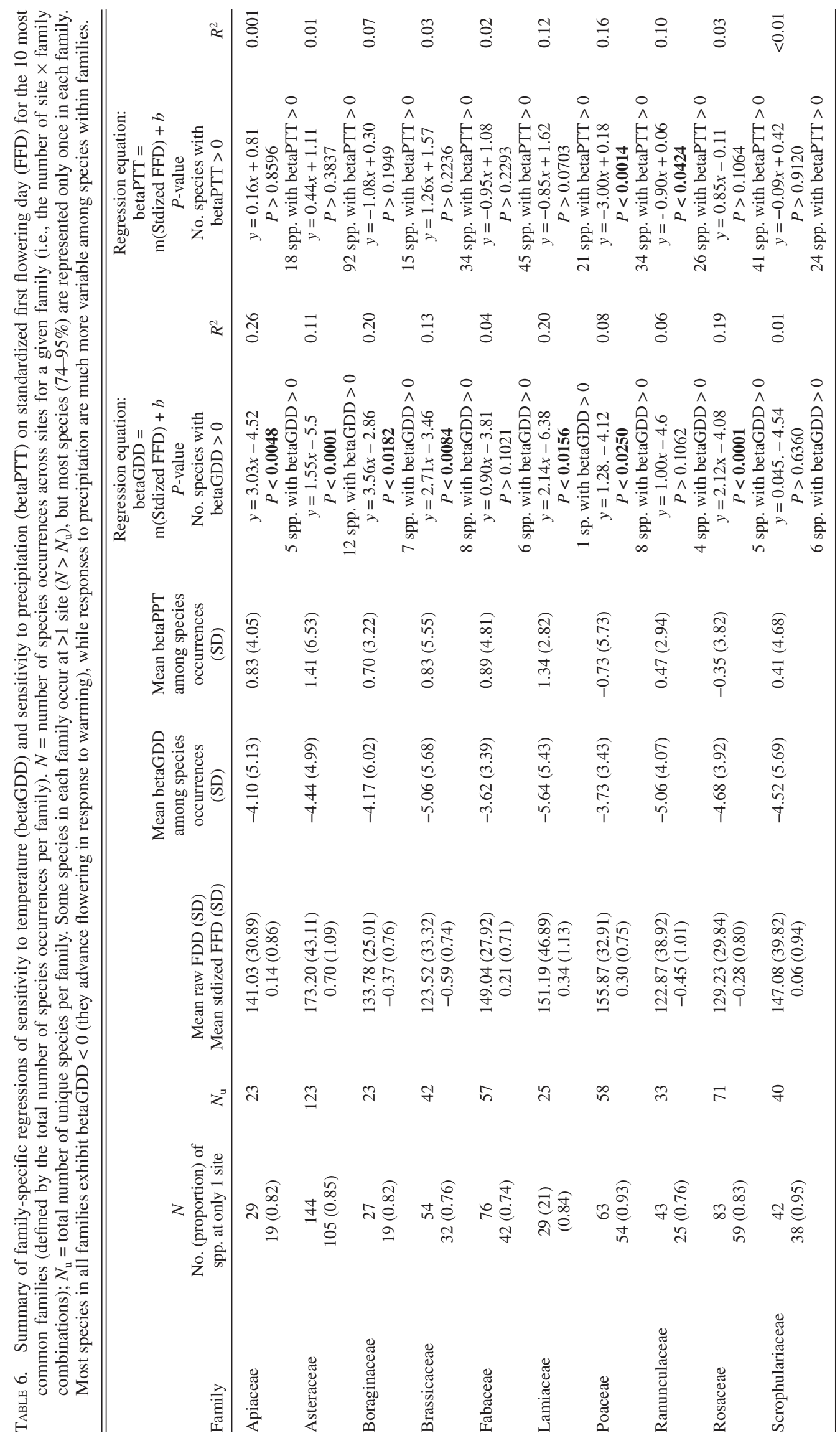




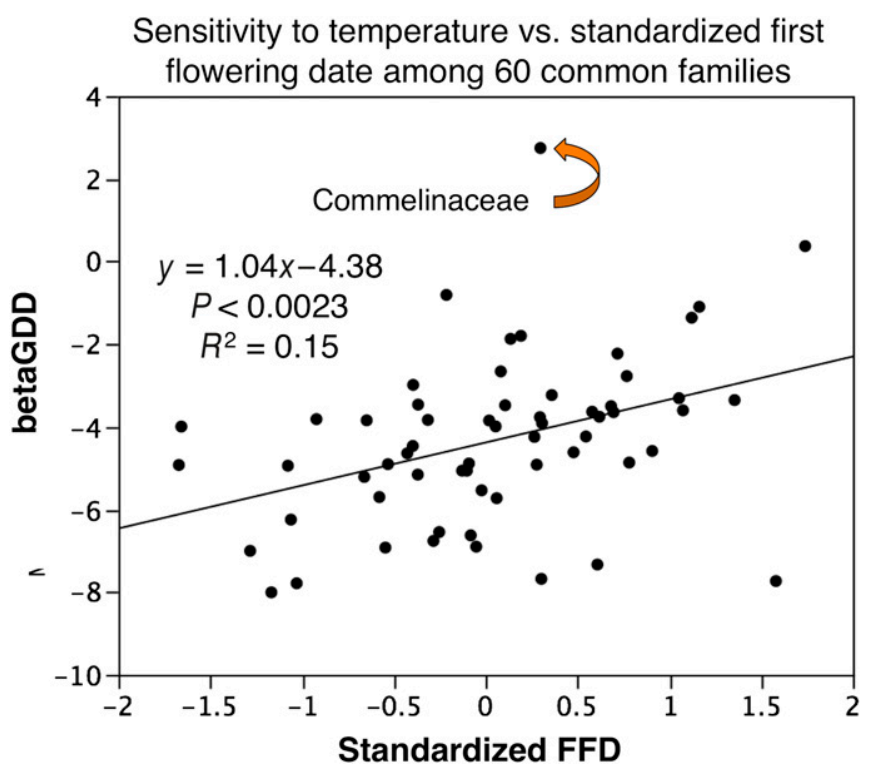

Fig. 6. Relationship between mean sensitivity to temperature (mean betaGDD) and mean standardized first flowering day (FFD) among 60 families represented at $\geq 3$ sites (every site $\times$ family combination included 1 or more species). Regression statistics shown here include the Commelinaceae (see text for results without this outlier). Early-flowering families are more sensitive to temperature and advance their FFD in response to warmer temperatures more than late-flowering families.

FFD in response to temperature. This raises the question of why the combination of early flowering and low sensitivity does not exist. In many populations, selection favors early-flowering individuals (Munguía-Rosas et al., 2011). We propose that the selective advantage of early flowering may often be a lower risk of floral or fruit damage by end-of-season frost rather than an advantage of a longer flowering period (cf. Pau et al., 2011).

If early flowering positively affects individual fitness or population persistence, then early-flowering individuals and species that are able to track accurately the transition from winter to spring in a manner that allows them to initiate flowering as soon as the risk of frost damage has passed will also be at an advantage. High sensitivity (and the phenotypic plasticity by which this is achieved: Nicotra et al., 2010; Anderson et al., 2012) to seasonal cumulative daily temperatures in winter and early spring is perhaps the most reliable way to mediate flowering time in a way that maximizes fitness (cf. Willis et al., 2008). Accordingly, early-flowering species that are not highly sensitive to temperature (those exhibiting weakly negative or positive betaGDD values) may be at an ecological or evolutionary disadvantage and more vulnerable to local or widespread extinction. By contrast, there is likely to be a lower advantage to high sensitivity to GDD for species flowering later in the season, when the cues for the initiation of the optimal flowering time should not necessarily be tightly correlated with fall or winter temperatures. In other words, among late-flowering individuals and taxa, selection favoring plasticity in FFD in response to temperature may be quite weak and instead may favor variants that bloom in response to alternative environmental cues or photoperiod (Cook et al., 2012a; Rollinson and Kaye, 2012).

Identifying taxa at risk-Identifying taxa that are, on average, characterized by low sensitivity to interannual variation in temperature (given their FFD) may allow preliminary predictions of which taxa may be more vulnerable to extinction in the face of climate change or severe climatic events. A residual analysis of the regression presented in Fig. 6 identifies nine families (excluding the outlying Commelinaceae) whose FFDs are less advanced (by 1.5 to $4 \mathrm{~d}$ per standardized deviation in GDD) than that predicted by their mean FFDs; their betaGDD values are 1.5-4 units above the regression line). These families are Amaryllidaceae (residual $=1.63$ ), Oxalidaceae (1.80), Clusiaceae (1.85), Onagraceae (2.07), Thymelaeaceae (2.11), Cornaceae (2.36), Plantaginaceae (2.38), Campanulaceae (2.94), and Iridaceae (3.79). Other studies have shown that advances in flowering in response to warming are positively associated with population persistence or abundance (Willis et al., 2008). Consequently, these families may be composed of taxa that are, demographically, relatively vulnerable to the effects of climate change. Alternatively, these taxa may be "divergent responders" (Cook et al., 2012a), exhibiting a relatively small change in FFD in response to warming as measured here. Tracking changes in the long-term abundances or demographic parameters of species in these families may elucidate the role that sensitivity plays in promoting population persistence or abundance.

Phenotypic plasticity in response to temperature enables plants to flower earlier than a strictly genetically controlled flowering time would permit (cf. Anderson et al., 2012; Brunet
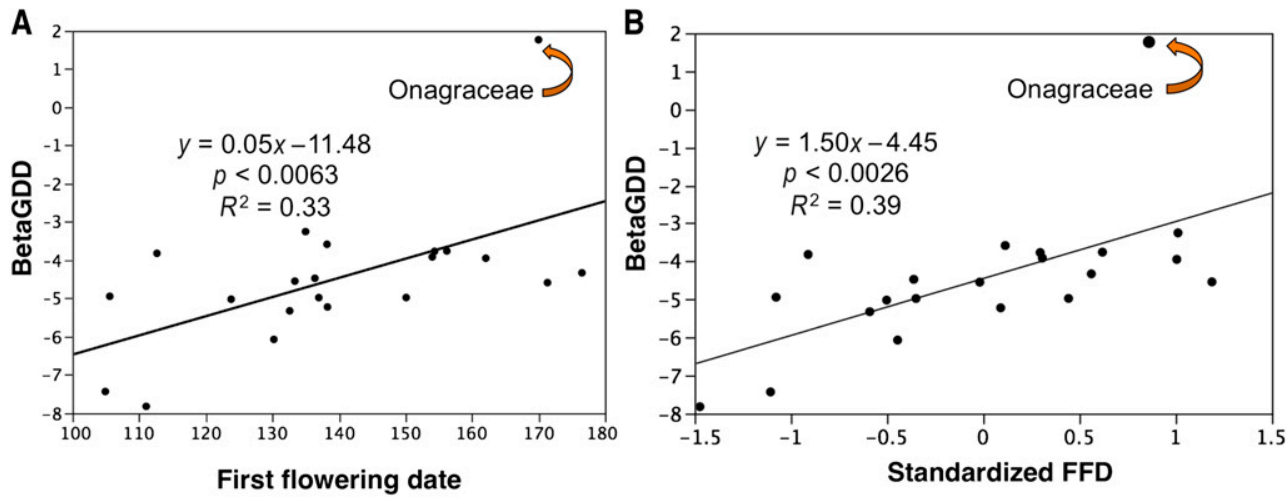

Fig. 7. Relationship between sensitivity to temperature (betaGDD) and (A) first flowering day (FFD) and (B) standardized FFD among 21 families represented by $\geq 3$ species at each of $\geq 3$ sites (every site $\times$ family combination included $\geq 3$ species). Regression statistics shown here include the Onagraceae (see text for regression results without this outlier). 

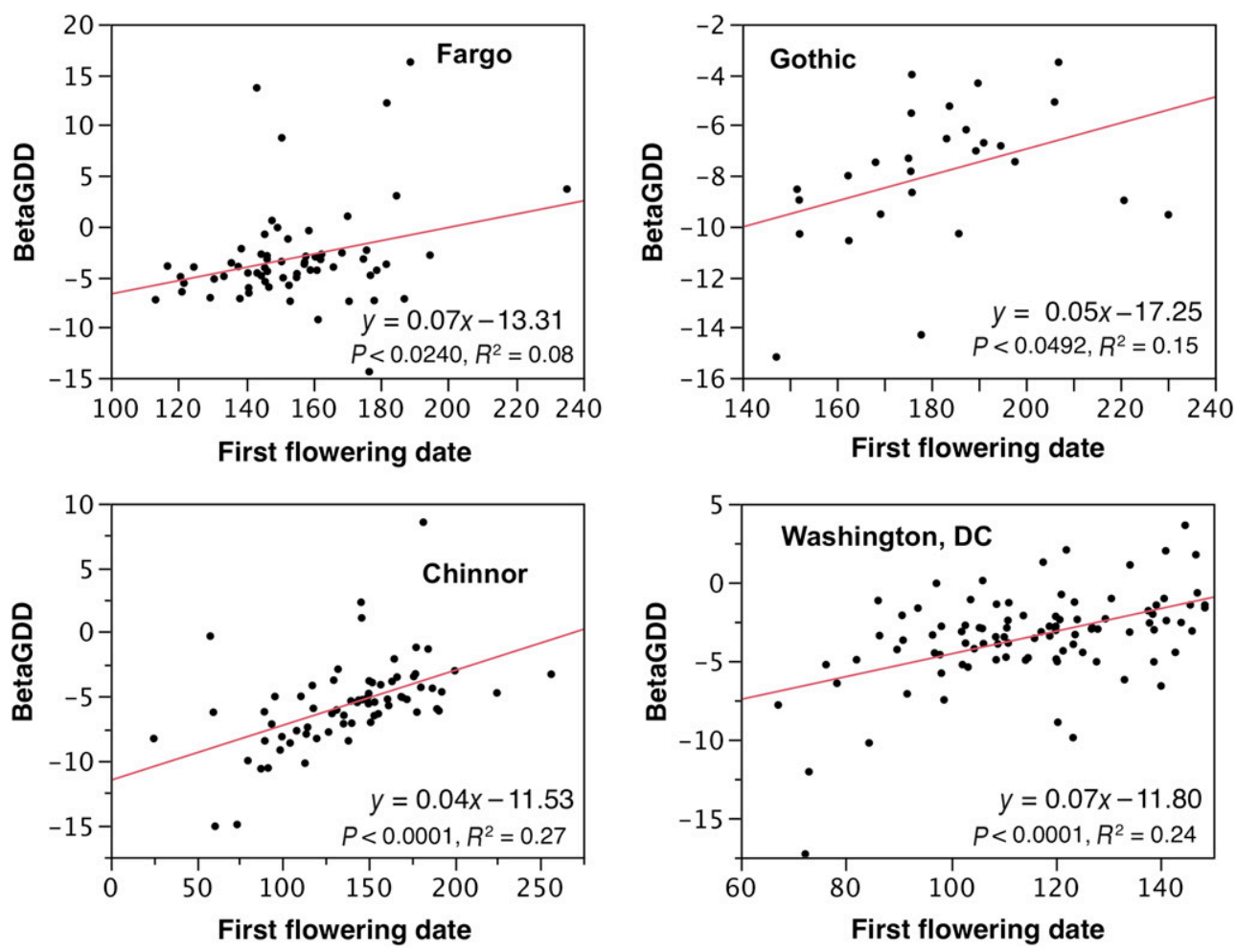

Fig. 8. Site-specific relationships among family means (1 or more species per family per site) between sensitivity to temperature (betaGDD) and first flowering date (FFD). Four of seven sites (shown here) exhibit a significant relationship; at these sites, early-flowering families advance flowering in response to high GDD more than late-flowering families. The other three sites exhibit no significant relationship among families between betaGDD and FFD, similar to the species-level relationships shown in Fig. 5.

and Larson-Rabin, 2012), so an individual's phenotypic plasticity in FFD is as much a target of selection as is its mean FFD. Whether the relatively low sensitivities of the families above negatively affects their long-term persistence remains an empirical question, but the patterns of species loss detected by Willis et al. (2008) in Concord, Massachusetts, suggest that local extirpation may well result from insufficiently plastic responses of flowering dates to temperature variation.
Conclusions-Taxonomic family membership can be used cautiously in concert with mean first flowering date to predict whether an unknown taxon will exhibit high vs. low sensitivity to temperature in seasonal, temperate zone plant communities. The particularly high sensitivity to temperature of species in families with early mean flowering times (and the absence of species observed in early-flowering families that delay flowering with increasing temperature) may reflect an adaptive advantage to early-flowering genotypes and taxa of responding
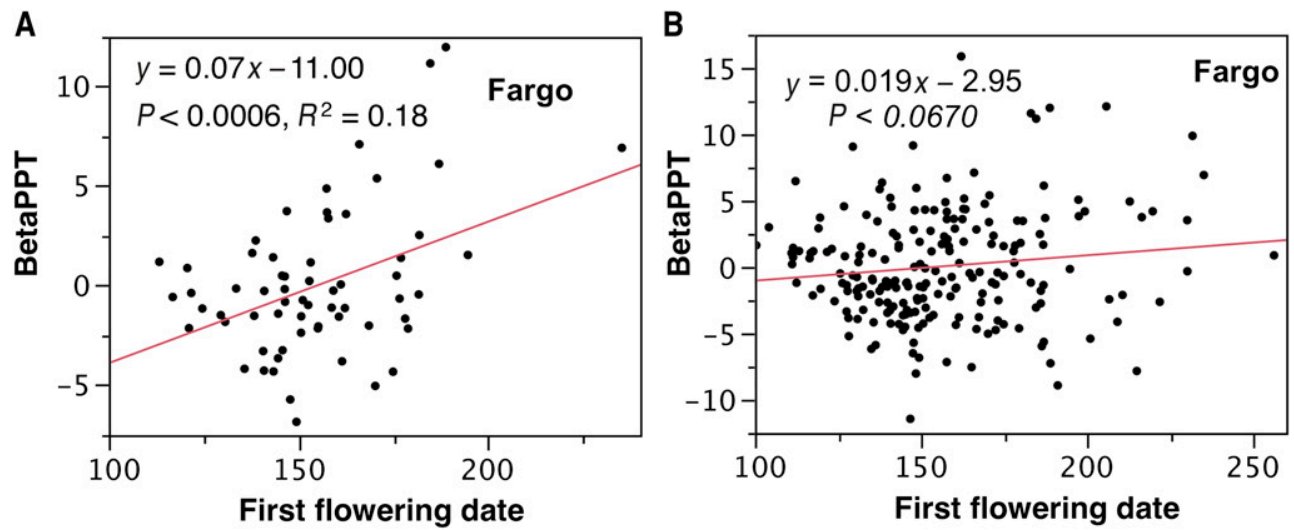

Fig. 9. Bivariate relationships between sensitivity to precipitation (betaPPT) and first flowering day (FFD) among (A) family means and (B) species at Fargo. At Fargo, early-flowering families tend to advance flowering (or to delay it less) in response to both GDD and PPT relative to late-flowering families. The relationship among species at Fargo is much weaker than the relationship among family means in spite of a much higher sample size at the species level. 
plastically to warmer /cooler temperatures by advancing/delaying FFD. A combination of long-term demographic studies, along with measures of species' phenological sensitivities to interannual variation in climate, however, is necessary to determine unambiguously the adaptive significance of interspecific variation in the magnitude and direction of phenological advances or delays in response to climate change.

\section{LITERATURE CITED}

Abu-Asab, M. S., P. M. Peterson, S. G. Shetler, and S. S. Orli. 2001. Earlier plant flowering in spring as a response to global warming in the Washington, DC, area. Biodiversity and Conservation 10: 597-612.

Aнas, R. 1999. Long-term phyto-, ornitho- and ichthyophenological timeseries analyses in Estonia. International Journal of Biometeorology 42: 119-123.

Ahas, R., And A. Aasa. 2006. The effects of climate change on the phenology of selected Estonian plant, bird and fish populations. International Journal of Biometeorology 51: 17-26.

Aldridge, G., D. W. Inouye, J. R. K. Forrest, W. A. Barr, and A. J. Miller-Rushing. 2011. Emergence of a mid-season period of low floral resources in a montane meadow ecosystem associated with climate change. Journal of Ecology 99: 905-913.

Amano, T., R. J. Smithers, T. H. Sparks, and W. J. Sutherland. 2010. A 250-year index of first flowering dates and its response to temperature changes. Proceedings of the Royal Society, B, Biological Sciences 277: 2451-2457.

Anderson, J., D. W. Inouye, A. M. McKinney, R. I. Colautti, and T. Mitchell-Olds. 2012. Phenotypic plasticity and adaptive evolution contribute to advancing flowering phenology in response to climate change. Proceedings of the Royal Society, B, Biological Sciences 279: 3843-3852.

Beaubien, E., and A. Hamann. 2011. Spring flowering response to climate change between 1936 and 2006 in Alberta, Canada. BioScience 61: $514-524$

BERTIN, R. I. 2008. Plant phenology and distribution in relation to recent climate change. Journal of the Torrey Botanical Society 135: 126-146.

Bolmgren, K., And P. D. Cowan. 2008. Time-size tradeoffs: A phylogenetic comparative study of flowering time, plant height and seed mass in a north-temperate flora. Oikos 117: 424-429.

Bolmgren, K., O. Eriksson, And H. P. Linder. 2003. Contrasting flowering phenology and species richness in abiotically and biotically pollinated angiosperms. Evolution 57: 2001-2011.

Bolmgren, K., And K. Lönnberg. 2005. Herbarium data reveal an association between fleshy fruit type and earlier flowering time. International Journal of Plant Sciences 166: 663-670.

Both, C., S. Bouwhuis, C. M. Lessells, and M. E. Visser. 2006. Climate change and population declines in a long-distance migratory bird. Nature 441: 81-83.

Both, C., AND M. E. Visser. 2001. Adjustment to climate change is constrained by arrival date in a long-distance migrant bird. Nature 411: 296-298.

Bradley, N. L., A. C. Leopold, J. Ross, and W. Huffaker. 1999. Phenological changes reflect climate change in Wisconsin. Proceedings of the National Academy of Sciences, USA 96: 9701-9704.

BRunet, J., AND Z. LARSON-RABIN. 2012. The response of flowering time to global warming in a high-altitude plant: The impact of genetics and the environment. Botany 90: 319-326.

Burger, C., E. Belskit, T. Eeva, T. Laaksonen, M. Magi, R. Mand, A. Ovarnstrom, ET AL. 2012. Climate change, breeding date and nestling diet: How temperature differentially affects seasonal changes in pied flycatcher diet depending on habitat variation. Journal of Animal Ecology 81: 926-936.

Cayan, D. R., S. A. Kammerdiener, M. D. Dettinger, J. M. Caprio, and D. H. Peterson. 2001. Changes in the onset of spring in the western United States. Bulletin of the American Meteorological Society 82: 399-415.
Chmielewski, F.-M., A. Müller, And E. Bruns. 2004. Climate changes and trends in phenology of fruit trees and field crops in Germany, 1961-2000. Agricultural and Forest Meteorology 121: 69-78.

Chung, U., L. Mack, J. I. Yun, AND S.-H. Kim. 2011. Predicting the timing of cherry blossoms in Washington, DC and Mid-Atlantic states in response to climate change. PLOS ONE 6: e27439.

Cleland, E. E., J. M. Allen, T. M. Crimmins, J. A. Dunne, S. Pau, S. E. Travers, E. S. Zavaleta, and E. M. Wolkovich. 2012. Phenological tracking enables positive species responses to climate change. Ecology 93: 1765-1771.

Cook, B. I., E. R. Cook, P. C. Huth, J. E. Thompson, A. Forster, And D. Smiley. 2008. A cross-taxa phenological dataset from Mohonk Lake, NY and its relationship to climate. International Journal of Climatology 28: 1369-1383.

Cook, B. I., E. M. Wolkovich, T. J. Davies, T. R. Ault, J. L. Betancourt, J. M. Allen, K. Bolmgren, et Al. 2012b. Sensitivity of spring phenology to warming across temporal and spatial climate gradients in two independent databases. Ecosystems (New York, N.Y.) doi:10.1007/ s10021-012-9584-5.

Cook, B. I., E. M. Wolkovich, and C. Parmesan. 2012a. Divergent responses to spring and winter warming drive community level flowering trends. Proceedings of the National Academy of Sciences, USA 109: 9000-9005.

Craine, J. M., E. M. Wolkovich, and E. G. Towne. 2012. The roles of shifting and filtering in generating community-level flowering phenology. Ecography 35: 1033-1038.

Davis, C. C., C. G. Willis, R. B. Primack, and A. J. Miller-Rushing. 2010. The importance of phylogeny to the study of phenological response to global climate change. Philosophical Transactions of the Royal Society, B, Biological Sciences 365: 3201-3213.

Diez, J., I. Ibáñ́tz, S. J. Mazer, T. Crimmins, M. Crimmins, and A. Miller-Rushing. 2012. Forecasting phenology: From species variability to community patterns. Ecology Letters 15: 545-553.

Doi, H., O. Gordo, and I. Katano. 2008. Heterogeneous intra-annual climatic changes drive different phenological responses at two trophic levels. Climate Research 36: 181-190.

Dunne, J. A., J. Harte, And K. J. TAYlor. 2003. Subalpine meadow flowering phenology responses to climate change: Integrating experimental and gradient methods. Ecological Monographs 73: 69-86.

Dunnell, K. L., and S. E. Travers. 2011. Shifts in the flowering phenology of the Northern Great Plains: Patterns over 100 years. American Journal of Botany 98: 935-945.

Durant, J. M., D. Ø. Huermann, G. Ottersen, and N. C. Stenseth. 2007. Climate and the match or mismatch between predator requirements and resource availability. Climate Research 33: 271-283.

Fitter, A. H., AND R. S. R. Fitter. 2002. Rapid changes in flowering time in British plants. Science 296: 1689-1691.

Fitter, A. H., R. S. R. Fitter, I. T. B. Harris, and M. H. Williamson. 1995. Relationships between first flowering date and temperature in the flora of a locality in central England. Functional Ecology 9: $55-60$.

Forrest, J., AND A. J. Miller-Rushing. 2010. Toward a synthetic understanding of the role of phenology in ecology and evolution. Philosophical Transactions of the Royal Society, B, Biological Sciences 365: 3101-3112.

Franks, S. J. 2011. Plasticity and evolution in drought avoidance and escape in the annual plant Brassica rapa. New Phytologist 190: 249-257.

Franks, S. J., S. Sim, and A. E. WeIs. 2007. Rapid evolution of flowering time by an annual plant in response to a climate fluctuation. Proceedings of the National Academy of Sciences, USA 104: 1278-1282.

Franks, S. J., AND A. E. Weis. 2008. A change in climate causes rapid evolution of multiple life-history traits and their interactions in an annual plant. Journal of Evolutionary Biology 21: 1321-1334.

Gilman, R. T., N. S. Fabina, K. C. Авbott, and N. E. Rafferty. 2011 Evolution of plant-pollinator mutualisms in response to climate change. Evolutionary Applications 5: 2-16.

Gordo, O., and J. J. Sanz. 2005. Phenology and climate change: A longterm study in a Mediterranean locality. Oecologia 146: 484-495. 
GoRdo, O., AND J. J. SANZ. 2009. Long-term temporal changes of plant phenology in the western Mediterranean. Global Change Biology 15: 1930-1948.

GoRDO, O., AND J. J. SANz. 2010. Impact of climate change on plant phenology in Mediterranean ecosystems. Global Change Biology 16: 1082-1106.

Harrington, R., I. Woiwod, and T. Sparks. 1999. Climate change and trophic interactions. Trends in Ecology \& Evolution 14: 146-150.

Hegland, S. J., A. Nielsen, A. Lazaro, A. L. BJerknes, and Ø. Totland. 2009. How does climate warming affect plant-pollinator interactions? Ecology Letters 12: 184-195.

Ho, C. H., E. J. Lee, I. LeE, AND S. J. Jeong. 2006. Earlier spring in Seoul, Korea. International Journal of Climatology 26: 2117-2127.

Iler, A. M., T. T. Hoye, D. W. Inouye, And N. M. Schmidt. 2013. Longterm trends mask variation in the direction and magnitude of short-term phenological shifts. American Journal of Botany 100: In press.

INOUYE, D. W. 2008. Effects of climate change on phenology, frost damage, and floral abundance of montane wildflowers. Ecology 89: 353-362.

Jones, T., AND W. CResswell. 2010. The phenology mismatch hypothesis: Are declines of migrant birds linked to uneven global climate change? Journal of Animal Ecology 79: 98-108.

KawaI, K., AND G. KUdD. 2011. Local differentiation of flowering phenology in an alpine-snowbed herb Gentiana nipponica. Botany 89: 361-367.

Knapp, A. K., J. M. Briggs, D. C. Hartnett, and S. L. Collins. 1998. Grassland dynamics: Long-term ecological research in tallgrass prairie. Oxford University Press, New York, New York, USA

Kochmer, J. P., AND S. N. Handel. 1986. Constraints and competition in the evolution of flowering phenology. Ecological Monographs 56: 303-325.

Leon, A. J., M. Lee, and F. H. Andrade. 2001. Quantitative trait loci for growing degree days to flowering and photoperiod response in sunflower (Helianthus annuus L.). Theoretical and Applied Genetics 102: 497-503.

MAZER, S. J. 1987. Quantitative genetics of life-history and fitness components in Raphanus raphanistrum L. (Brassicaceae): Ecological and evolutionary consequences of seed weight variation. American Naturalist 130: 891-914.

Mazer, S. J., And G. L. Lebuhn. 1999. The genetic basis of life history traits in plants: Heritability within and genetic differentiation among populations. In P. Mutakainin and T. Vuorisalo [eds.], Life history evolution in plants, 85-171. Kluwer, Dordrecht, Netherlands.

McKinney, A. M., P. J. CaraDonna, D. W. Inouye, B. Barr, C. D. BERTElsen, AND N. M. Waser. 2012. Asynchronous changes in phenology of migrating Broad-tailed hummingbirds and their early-season nectar resources. Ecology 93: 1987-1993.

Menzel, A. 2000. Trends in phenological phases in Europe between 1951 and 1996. International Journal of Biometeorology 44: 76-81.

Menzel, A., T. H. Sparks, N. Estrella, E. Кoch, A. Aasa, R. Ahas, K. Alm-Kübler, et AL. 2006a. European phenological response to climate change matches the warming pattern. Global Change Biology 12: 1969-1976.

Menzel, A., T. H. Sparks, and D. B. Roy. 2006b. Altered geographic and temporal variability in phenology in response to climate change. Global Ecology and Biogeography 15: 498-504.

Miller-Rushing, A. J. T., ANd D. W. Inouye. 2009. Variation in the impact of climate change on flowering phenology and abundance: An examination of two pairs of closely related wildflower species. American Journal of Botany 96: 1821-1829.

Miller-Rushing, A. J., T. Katsuki, R. B. Primack, Y. Ishit, S. D. Lee, AND H. Higuchi. 2007. Impact of global warming on a group of related species and their hybrids: cherry tree (Rosaceae) flowering at Mt. Takao, Japan. American Journal of Botany 94: 1470-1478.

Miller-Rushing, A. J., AND R. B. Primack. 2008. Global warming and flowering times in Thoreau's Concord: A community perspective. Ecology 89: 332-341.

Munguía-Rosas, M. A., J. Ollerton, V. Parra-Tabla, and J. Arturo De-Nova. 2011. Meta-analysis of phenotypic selection on flowering phenology suggests that early flowering plants are favored. Ecology Letters 14: 511-521.
Myneni, R. B., C. D. Keeling, C. J. Tucker, G. Asrar, and R. R. NEMANI. 1997. Increased plant growth in the northern latitudes from 1981 to 1991. Nature 386: 698-702.

Nicotra, A. B., O. K. Atkin, S. P. Bonser, A. M. Davidson, E. J. Finnegan, U. Mathesius, P. Роот, et al. 2010. Plant phenotypic plasticity in a changing climate. Trends in Ecology \& Evolution 15: 684-692.

Olsson, K., AND J. ÅgREn. 2002. Latitudinal population differentiation in phenology, life history and flower morphology in the perennial herb Lythrum salicaria. Journal of Evolutionary Biology 15: 983-996.

PARMESAN, C. 2006. Ecological and evolutionary responses to recent climate change. Annual Review of Ecology, Evolution and Systematics 37: 637-669.

Parmesan, C., and G. Yohe.. 2003. A globally coherent fingerprint of climate change impacts across natural systems. Nature 421: 37-42.

Pau, S., E. M. Wolkovich, B. I. Cook, T. J. Davies, N. J. B. Kraft, K. Bolmgren, J. L. Betancourt, and E. E. Cleland. 2011. Predicting phenology by integrating ecology, evolution and climate science. Global Change Biology 17: 3633-3643.

Richardson, A. D., A. S. Bailey, E. G. Denny, C. W. Martin, and J. O'KeEFE. 2006. Phenology of a northern hardwood forest canopy. Global Change Biology 12: 1174-1188.

Rollinson, C. R., AND M. W. KaYe. 2012. Experimental warming alters spring phenology of certain plant functional groups in an early successional forest community. Global Change Biology 18: 1108-1116.

Roetzer, T., M. Wittenzeller, H. Haeckel, and J. Nekovar. 2000. Phenology in central Europe-differences and trends in spring phenophases in urban and rural areas. International Journal of Biometeorology 44: 60-66.

Scheifinger, H., A. Menzel, E. Koch, and C. Peter. 2003. Trends of spring time frost events and phenological dates in Central Europe. Theoretical and Applied Climatology 74: 41-51.

Scheifinger, H., A. Menzel, E. Koch, C. Peter, and R. Ahas. 2002. Atmospheric mechanisms governing the spatial and temporal variability of phenological phases in central Europe. International Journal of Climatology 22: 1739-1755.

Schemske, D. W. 1977. Flowering phenology and seed set in Claytonia virginica (Portulacaceae). Bulletin of the Torrey Botanical Club 104: 254-263.

Sparks, T. H., and P. D. Carey. 1995. The responses of species to climate over two centuries: An analysis of the Marsham phenological record, 1736-1947. Journal of Ecology 83: 321-329.

Sparks, T. H., E. P. Jefrree, and C. E. Jefreree. 2000. An examination of the relationship between flowering time and temperature at the national scale using long-term phenological records from the UK. International Journal of Biometeorology 44: 82-87.

Stevens, O. A. 1961. Plants of Fargo, North Dakota. American Midland Naturalist 66: 171-177.

Stinchcombe, J. R., C. Weinig, M. Ungerer, K. M. Olsen, C. Mays, S. S. Halldorsdottir, M. D. Purugganan, and J. Schmitt. 2004. A latitudinal cline in flowering time in Arabidopsis thaliana modulated by the flowering time gene FRIGIDA. Proceedings of the National Academy of Sciences, USA 101: 4712-4717.

Strode, P. K. 2003. Implications of climate change for North American wood warblers (Parulidae). Global Change Biology 9: 1137-1144.

Travers, S. E., K. L. Dunnell, and W. K. Michener. 2009. Firstflowering dates of plants in the Northern Great Plains. Ecology 90: 2332.

VisSer, M. E., AND C. Both. 2005. Shifts in phenology due to global climate change: The need for a yardstick. Proceedings of the Royal Society, B, Biological Sciences 272: 2561-2569.

Willis, C. G., B. Ruhfel, R. B. Primack, A. J. Miller-Rushing, and C C. DAVIS. 2008. Phylogenetic patterns of species loss in Thoreau's woods are driven by climate change. Proceedings of the National Academy of Sciences, USA 105: 17029-17033.

Willis, C. G., B. R. Ruhfel, R. B. Primack, A. J. Miller-Rushing, J. B. Losos, AND C. C. DAvis. 2010. Favorable climate change response explains non-native species' success in Thoreau's woods. PLOS ONE 5: e8878. 
Winder, M., And D. E. Schindler. 2004. Climate change uncouples trophic interactions in an aquatic ecosystem. Ecology 85: 2100-2106.

WIPF, S. 2010. Phenology, growth, and fecundity of eight subarctic tundra species in response to snowmelt manipulations. Plant Ecology 207: 53-66.

Wolkovich, E. M., B. I. Cook, J. M. Allen, T. M. CRimmins, J. L. Betancourt, S. E. Travers, S. PAU, et AL. 2012. Warming experiments underpredict plant phenological responses to climate change. Nature 485: 494-497.

Wright, V. 2001. Prairies phenology. Technical Report, Konza Environmental Education Program, Konza Prairie Biological Station, Manhattan, Kansas, USA.

Zhang, X., D. Tarpley, and J. T. Sullivan. 2007. Diverse responses of vegetation phenology to a warming climate. Geophysical Research Letters 34: L19405. 